\title{
Systemic risk in the European sovereign and banking system
}

\author{
Simon $\mathrm{Xu}^{\mathrm{a}}$, Francis In, Catherine Forbes, and Inchang Hwang ${ }^{\mathrm{d}}$
}

\begin{abstract}
We investigate the systemic risk of the European sovereign and banking system during 2008-2013. We utilize a conditional measure of systemic risk that reflects market perceptions and can be intuitively interpreted as an entity's conditional joint probability of default, given the hypothetical default of other entities. The measure of systemic risk is applicable to high dimensions and not only incorporates individual default risk characteristics but also captures the underlying interdependent relations between sovereigns and banks in a multivariate setting. In empirical applications, our results reveal significant time variation in systemic risk spillover effects for the sovereign and banking system. We find that systemic risk is mainly driven by risk premiums coupled with a steady increase in physical default risk.
\end{abstract}

Keywords: Systemic risk; Sovereign default; Banking stability; Tail risk

JEL Classification: C16, C61, G01, G21

\footnotetext{
${ }^{a}$ Department of Banking and Finance, Monash Business School, Monash University, Clayton, VIC 3800, Australia; email simon.xu@monash.edu.

${ }^{\mathrm{b}}$ Corresponding author: Department of Banking and Finance, Monash Business School, Monash University, Clayton, VIC 3800, Australia; tel. (+61) 39905 1561; fax (+61) 39905 5475; email francis.in@monash.edu.

${ }^{\mathrm{c}}$ Department of Econometrics and Business Statistics, Monash Business School, Monash University, Clayton, VIC 3800, Australia; email catherine.forbes@monash.edu.

${ }^{\mathrm{d}}$ Korea Insurance Research Institute, KFPA Bldg, 38, Gukjegeumyung-ro 6-gil, Youngdeungpo-gu, Seoul, 07328, South Korea; email hic7217@kaist.ac.kr.
} 


\section{Introduction}

One of the most critical issues in current debates is the looming possibility of a sovereign default in the euro area (EA). Regulators and policymakers fear that vulnerabilities in the peripheral European countries - namely, Greece, Ireland, Italy, Portugal, and Spain - could potentially spread to the rest of Europe. At the same time, European leaders are wrestling with the prospect of the failure of systemically important banks and its consequences on the European banking system. With the rise of the sovereign debt crisis, the interdependence between sovereigns and banks has greatly intensified, causing fears of negative feedback loops between the two systems. Against this backdrop, the need to identify the level of systemic risk in a multivariate system consisting of both sovereigns and banks becomes increasingly apparent.

Although there is no universal definition of systemic risk, a recurring theme throughout the systemic risk literature is that true systemic events impact the entire system (Billio, Getmansky, Lo, \& Pelizzon, 2012). At its core, systemic risk is associated with the risk due to the interdependence between financial entities; systemic events do not necessarily have to stem from a causal origin. In this paper, we utilize the conditional joint probability of default proposed by Radev (2013) as our definition of systemic risk. We extend Radev's (2013) methodology to estimate the conditional joint probability of default in higher-order dimensions and assess the market perceptions of the effects of sovereign and bank default on the European sovereign and banking system. The measure of systemic risk we employ can be interpreted as an entity's conditional joint probability of default, given the (hypothetical) default of other entities within the system. The advantage of a conditional measure is that it captures not only an entity's individual default risk characteristics but also reflects the dynamics of its joint default risk due to its interdependence with other entities.

Our focus on the European sovereign and banking system is not coincidental but is motivated by their extensive interdependencies. Until recently, for many years, there had been no credit risk for sovereign debt in developed countries. Prior to the global financial crisis of 2007-2009, most European banking regulations focused on individual banks and the risk on their balance sheets. This form of regulation turned out to be flawed, since it ignores the systemic relation between the sovereign and banking systems. For example, Gerali, Neri, Sessa, and Signoretti (2010) show that the largest contribution to the contraction of EA economic activity in 2008 had been due to shocks originating from the banking sector. The onset of the sovereign debt crisis saw the relation between banks and sovereigns escalate to a new level. The Greek default in 2011 showed that there is credit risk in holding sovereign debt. Among the bailout packages were substantial write-offs of Greek debt in the books of private investors, most of which were held by banks. As the sovereign debt crisis evolved, European banks were confronted with liquidity dry-ups and stress in their capital positions. The European Banking Authority's (EBA) stress test results in 2011 revealed that banks in peripheral sovereigns were unlikely to weather negative shocks to the sovereign system, given their sovereign debt exposure. Overall, the combined effect 
of the vulnerability of certain sovereigns and the continued stress in the banking system meant that the financial conditions of banks and sovereigns had become increasingly intertwined.

The literature has proposed various measures of systemic risk (e.g., Acharya, Pedersen, Philippon, \& Richardson, 2010; Adrian \& Brunnermeier, 2011; Brownlees \& Engle, 2012; C. Chen, Iyengar, \& Moallemi, 2013; Engle, Jondeau, \& Rockinger, 2015; Hautsch, Schaumburg, \& Schienle, 2015; Huang, Zhou, \& Zhu, 2009; Puzanova \& Düllmann, 2013). Bisias, Flood, Lo, and Valavanis (2012) provide a comprehensive overview. The common theme among these studies is the estimation of the magnitude of losses conditional on the simultaneous distress of other institutions. While such measures may capture the systemic risk of entities in isolation, the situation becomes more problematic if one considers the interactions of these entities with the rest of the system. For example, during a sovereign debt crisis, the cost of debt refinancing in one EA sovereign can depend on the perceived developments in multiple other sovereigns. By using a probabilistic measure of systemic risk, we are able to provide answers to questions of what if? Specifically, we can investigate market perceptions regarding the conditional probability of default of sovereigns and/or banks given the default of other sovereigns and/or banks. Such an analysis allows inference, for example, on which sovereigns market participants consider to be more exposed to certain credit events than others are.

Our study is most closely related to several other recent studies that also utilize probabilistic measures to gauge the systemic risk of the EA. Radev (2013) uses the change in the conditional joint probability of default and documents an increase in systemic risk contributions due to interdependence in the EA during the European sovereign debt crisis. Lucas, Schwaab, and Zhang (2014) propose a dynamic skewed $t$-distribution to assess the likelihood of joint and conditional sovereign default from observed credit default swap (CDS) prices. Pianeti and Giacometti (2015) introduce a multivariate model based on bond and CDS data to estimate the joint probabilities of default of multiple sovereigns within the EA. Our study differs from the aforementioned studies since we focus on the systemic risk of higher dimensions. For example, Lucas et al. (2014) and Pianeti and Giacometti (2015) focus only on the systemic risk of the European sovereign system and estimate their systemic risk measures for samples consisting of 10 and 11 sovereigns, respectively. Our study examines the systemic risk of both the sovereign and banking systems by using a sample of 14 sovereigns and 40 banks. Although Radev's (2013) study also examines the systemic risk of the sovereign and banking systems, it is restricted by its estimation methodology that precludes the possibility of examining systemic risk in higher dimensions. ${ }^{1}$ Our paper is also related to a recent study by Betz, Hautsch, Peltonen, and Schienle (2015) that extends the methodology of Hautsch et al. (2015) to examine systemic risk spillover between European sovereigns and banks in a high-dimensional system. The authors document time-varying systemic risk spillover between sovereigns and banks during the global financial

\footnotetext{
${ }^{1}$ For example, when examining the impact of peripheral sovereign defaults on the banking system, Radev (2013) splits a sample of 36 banks into nine portfolios consisting of four banks each. Using Spain as the default trigger, the paper examines the joint probability of default of each bank portfolio conditional on Spain's default, effectively reducing the model to a five-dimensional problem.
} 
crisis and the European sovereign debt crisis. Most notably, they find increased interdependence between sovereigns and banks during the European sovereign debt crisis.

Our main findings can be summarized as follows. Applying the measure of systemic risk to the sovereign system, we confirm the perceived importance of core sovereigns in maintaining the stability of the EA. We also show that peripheral sovereigns are perceived to be the least resilient to sovereign system default. Shifting our focus to the systemic impact of peripheral sovereigns, our results indicate that market participants perceive not only a large degree of systemic risk spillover within the peripheral sovereign system but also the potential for systemic risk to spill over from peripheral sovereigns to core sovereigns. Applying our measure of systemic risk in the European banking system reveals that, of the EA banks, French banks contributed the most to the systemic risk of the banking system during both the global financial crisis and the sovereign debt crisis. However, banks in the larger peripheral sovereigns, such as Italy and Spain, were also perceived by market participants to be systemically risky. Merging the sovereign and banking systems into a single multivariate system and using sovereigns as the default trigger, we show that the evolution of the conditional joint probability of default of the banking system coincides with major events throughout our sample period. Finally, we show that the systemic risk of the sovereign system is driven not only by the default risk premium and the sovereign risk premium, but also by the banking system's physical probabilities of default.

\section{Methodology}

\subsection{Conditional joint probability of default}

We begin by recalling the definition of the conditional joint probability of default (CoJPoD) introduced by Radev (2013). Assume $n$ entities (or institutions) in the system and let $X_{1}, X_{2}, \cdots, X_{n}$ denote the random variables corresponding to the natural logarithm of assets of institution $I_{1}, I_{2}, \cdots, I_{n}$, respectively. An institution is in default if its logarithm of assets falls below a certain threshold, which we denote $X_{d}^{I_{i}}$. The marginal probability of default is given by ${ }^{2}$

$$
\operatorname{PoD}_{I_{i}}=P\left(X_{i} \geq X_{d}^{I_{i}}\right)=\int_{-\infty}^{\infty} \cdots \int_{X_{d}^{I_{i}}}^{\infty} \cdots \int_{-\infty}^{\infty} \int_{-\infty}^{\infty} p\left(x_{1}, x_{2}, \cdots, x_{n}\right) d x_{1} d x_{2} \cdots d x_{i} \cdots d x_{n}
$$

where $p\left(x_{1}, x_{2}, \cdots, x_{n}\right)$ is the joint probability density function describing the $n$-dimensional system.

The above definition gives the theoretical probability of default of institution $I_{i}$. However, since the underlying asset structure of an institution evolves stochastically throughout time, the default threshold will also change throughout time. Following Segoviano (2006), we define the

\footnotetext{
${ }^{2}$ For computational convenience, the default region is defined to be in the right tail of the density function.
} 
fixed time average default threshold of institution $I_{i}$ as

$$
X_{d}^{I_{i}}=\Phi^{-1}\left(1-\overline{P o D_{I_{i}}}\right)
$$

where $\Phi^{-1}(\cdot)$ denotes the standard inverse normal cumulative function and $\overline{P o D_{I_{i}}}$ is the time average empirical probability of default of institution $I_{i}$, estimated by bootstrapping CDS spreads. Since the default threshold is fixed, we vary the underlying probability distribution throughout time so that each point in time is described by a unique density function.

Define the joint probability of default $(J P o D)$ of $n$ entities as

$$
\begin{aligned}
J P_{o} D_{\left\{I_{1}, I_{2}, \cdots, I_{n}\right\}} & =P\left(X_{1} \geq X_{d}^{I_{1}}, X_{2} \geq X_{d}^{I_{2}}, \cdots, X_{n} \geq X_{d}^{I_{n}}\right) \\
& =\int_{X_{d}^{I_{n}}}^{\infty} \cdots \int_{X_{d}^{I_{2}}}^{\infty} \int_{X_{d}^{I_{1}}}^{\infty} p\left(x_{1}, x_{2}, \cdots, x_{n}\right) d x_{1} d x_{2} \cdots d x_{n} \\
& =J P o D_{\text {system }}
\end{aligned}
$$

By construction, $J P o D_{\text {system }}$ is an unconditional measure, since it does not explicitly account for the negative spillover effects of default but, rather, reflects the system's fragility to default shocks.

The CoJPoD of the system given the default of institution $I_{k}$ is then

$$
\begin{aligned}
& \operatorname{CoJPoD}_{\left\{I_{1}, \cdots, I_{k-1}, I_{k+1}, \cdots, I_{n}\right\} \mid I_{k}} \\
& =\operatorname{CoJPoD}_{\left\{\text {system } \backslash I_{k}\right\} \mid I_{k}} \\
& =P\left(X_{1} \geq X_{d}^{I_{1}}, \cdots, X_{k-1} \geq X_{d}^{I_{k-1}}, X_{k+1} \geq X_{d}^{I_{k+1}}, \cdots, X_{n} \geq X_{d}^{I_{n}} \mid X_{k} \geq X_{d}^{I_{k}}\right) \\
& =\frac{J P o D_{\left\{I_{1}, I_{2}, \cdots, I_{n}\right\}}}{\operatorname{PoD}_{I_{k}}} \\
& =\frac{J P o D_{\text {system }}}{\operatorname{PoD}_{I_{k}}}
\end{aligned}
$$

This expression shows that $\operatorname{CoJPoD}_{\left\{\text {system } \backslash I_{k}\right\} \mid I_{k}}$ is the default likelihood of the remaining institutions within the system given the default of a particular institution. It can be computed as the ratio of the system's joint probability of default to the marginal probability of default of a particular institution. We can interpret $\operatorname{CoJPoD} D_{\left\{\text {system } \backslash I_{k}\right\} \mid I_{k}}$ as the contribution of institution $I_{k}$ 's default on the system's overall systemic risk.

The term CoJPoD is a measure of systemic risk due to interdependence rather than causality; this is an ideal property to have when attempting to quantify systemic risk. For instance, the failure of a few entities may not be systemic, but the failure of a single highly interdependent entity can be. In other words, the default of a group of entities may not necessarily cause the rest of the system to default. However, if the default is a result of a common factor, then the rest of the system will be more likely to default due to the systemic nature of the initial shock. Therefore, in the absence of causality, each individual entity's default risk should co-vary with 
the rest of the system's default risk due to the underlying interdependent relations between the entities. The CoJPoD measure captures this subtle aspect of systemic risk.

\subsection{Estimating the marginal probability of default}

The first ingredient of CoJPoD consists of deriving each entity's marginal probability of default. We extract marginal probabilities of default from CDS spreads by applying the bootstrapping procedure outlined by Hull and White (2000). There are four main advantages to using CDS spreads to estimate probabilities of default. First, estimation of $P o D$ values from CDS spreads is not subject to the modelling of the distribution of asset values or the explicit estimation of asset correlations. Second, CDS spreads provide timelier market-based valuations, since CDS markets react to changes in default expectations in real time (Bruyckere, Gerhardt, Schepens, \& Vennet, 2013). Third, CDS spreads are forward looking, in the sense that they frequently anticipate rating changes and closely track future fiscal deficits. Finally, CDS spreads are less affected by liquidity and flight-to-safety issues when compared to Treasury bonds.

Since the bootstrapping procedure that we utilize is a standard method in financial practice, we only outline our choices in the implementation. The procedure requires three main inputs: CDS maturities, discount rates, and recovery rates. We use daily CDS spreads with maturities of one to five years and daily AAA EA sovereign bond yields with maturities of three months to five years for the discount rates. As discussed below, the discount rates are treated as risk-free rates, since the bootstrapped probabilities of default are risk-neutral measures. ${ }^{3}$ Following prior literature, we set a constant recovery rate of $40 \%$ (Sturzenegger \& Zettelmeyer, 2008). The bootstrapping procedure begins with an iterative process whereby we assume a constant hazard rate function and build a probability curve using the CDS contract with the shortest maturity (one year). From this, we extend the probability curve to the CDS contract with the next longest maturity (two years), again assuming a constant hazard rate function. We continue this process until we reach the CDS contract with the longest maturity (five years). At each step of the recursive process, we ensure that the no-arbitrage condition is satisfied by equating the premium leg with the payoff leg. ${ }^{4}$ Consequently, because the recovered term structure of hazard rates is arbitrage free, we obtain risk-neutral probabilities of default. In other words, the probabilities of default not only reflect physical probabilities of default but also contain information on any associated risk premium components. We take full advantage of this property when examining the decomposition of CoJPoD. We annualize the $P o D$ values to align with the one-year horizon of interest of policymakers.

\footnotetext{
${ }^{3}$ The AAA EA sovereign bond yields are obtained from the European Central Bank's (ECB) index of AAA-rated sovereign bonds of the EA sovereigns. To ensure that the sovereign bond yields are appropriate proxies for risk-free rates, we verify that none of the reference entities of the sovereign CDS contracts are used in the construction of the index.

${ }^{4}$ A CDS contract has two legs: a premium leg and a payoff leg. The former is the premium that buyers pay to insure themselves against possible defaults of the reference entity. The latter represents the payoff to buyers in the case in which the reference entity defaults. The payoff equals the difference between the face value of the reference entity and its recovered value. If the reference entity does not default over the maturity of the CDS contract, the payoff is zero.
} 


\subsection{Estimating the multivariate joint distribution}

The bootstrapped $P o D$ values represent individual default risk perceptions. We now extend Radev's (2013) estimation methodology to higher dimensions by implementing a procedure that transforms these marginal probabilities of default into joint probabilities of default by imposing a dynamic dependence structure between the system's individual entities. There are numerous approaches to modelling joint default risk (e.g., Avesani, Pascual, \& Li, 2006; Bams \& Wielhouwer, 2000; Cai, Einmahl, Haan, \& Zhou, 2015; Lucas et al., 2014). However, most involve the calibration of dependence structures that rely on the evolution of an institution's capital structure. In a true multivariate context consisting of banks and sovereigns, the value of sovereign assets is not directly observable. We use the consistent information multivariate density optimization (CIMDO) methodology introduced by Segoviano (2006) to estimate joint probabilities of default.

The CIMDO methodology recovers multivariate joint distributions without taking any stance on the observability of sovereign assets. The key improvements of the CIMDO procedure over traditional risk models is that it captures both linear and non-linear distress dependencies between entities in the system and allows for these to change throughout time, reflecting the fact that dependence differs during tranquil times and periods of distress. The underlying idea of the CIMDO approach is that any multivariate density that characterizes the stochastic behaviour of a group of random variables can be broken into two subsets of information: (1) the marginal distribution of each random variable and (2) the underlying dependence structure between random variables. To recover the latter, instead of assuming parametric distributions to fit available information, the CIMDO approach uses all available data to calibrate a non-parametric distribution. Such an approach minimizes the possibility of misspecification and ensures that the resulting distribution is always consistent with empirical data.

We begin by specifying a prior (or ex ante) joint density function, denoted $q\left(x_{1}, x_{2}, \cdots, x_{n}\right) \in$ $\mathbb{R}^{n}$, to describe the underlying dependence structure between the entities within the system. This prior distribution is then updated by inferring indirect and partial information from the bootstrapped $P o D$ values, which produces a posterior (or ex post) distribution, denoted $p\left(x_{1}, x_{2}, \cdots, x_{n}\right) \in \mathbb{R}^{n}$. This updating process involves adjusting the probability mass in the tails of the prior density function such that its tail probability is consistent with the marginal probabilities of default. This problem can be formulated by minimizing the functional

$$
\iint \cdots \int p\left(x_{1}, x_{2}, \cdots, x_{n}\right) \ln \left[\frac{p\left(x_{1}, x_{2}, \cdots, x_{n}\right)}{q\left(x_{1}, x_{2}, \cdots, x_{n}\right)}\right] d x_{1} \cdots d x_{n-1} d x_{n}
$$


with respect to $p$, subject to the following moment consistency constraints: ${ }^{5}$

$$
\begin{gathered}
\iint \cdots \int p\left(x_{1}, x_{2}, \cdots, x_{n}\right) \chi_{\left[X_{d}^{I_{i}}, \infty\right)} d x_{1} \cdots d x_{n-1} d x_{n}=P o D_{I_{i}} \\
\iint \cdots \int p\left(x_{1}, x_{2}, \cdots, x_{n}\right) d x_{1} \cdots d x_{n-1} d x_{n}=1
\end{gathered}
$$

where $\chi_{\left[X_{d}^{I_{i}}, \infty\right)}=1$ if $X_{i} \geq X_{d}^{I_{i}}$ and zero otherwise, for $i=1,2, \cdots, n$. The optimal solution is given by

$$
p\left(x_{1}, \widehat{x_{2}, \cdots}, x_{n}\right)=q\left(x_{1}, x_{2}, \cdots, x_{n}\right) \exp \left\{-\left[1+\widehat{\mu}+\sum_{i=1}^{n} \widehat{\lambda}_{i} \chi_{\left[X_{d}^{I_{i}}, \infty\right)}\right]\right\}
$$

where $\widehat{\lambda_{1}}, \widehat{\lambda_{2}}, \cdots, \widehat{\mu}$ denote consistent estimators of the Lagrange multipliers for the $n$ moment consistency constraints and the unity constraint, respectively.

We continue this iterative process by updating the prior density function on a daily basis. The resulting posterior density function exhibits fat tail properties and is dynamic by construction. An important facet of this approach is that we do not have to explicitly specify what constitutes sovereign assets or liabilities when quantifying sovereign default risk. Since we effectively reverse-engineer the joint probability distribution describing the system, we simply rely on the bootstrapped probabilities of default to proxy for the system's underlying asset process. As a result, when equation (4) is used to compute conditional joint probabilities of default, each entity's marginal probability of default acts as a common denominator, allowing us to pool banks and sovereigns together to form a single multivariate system. ${ }^{6}$

As Segoviano (2006) shows, using a multivariate standard normal distribution as the prior distribution is sufficient to explain the behaviour in the default region of the posterior distribution. Furthermore, the author demonstrates that the CIMDO methodology is highly robust to various prior distributions and employing more complex prior distributions such as the multivariate $t$ distribution or a mixture of normal distributions produces very similar tail regions in the posterior distribution. Thus, we choose the multivariate normal distribution as the prior distribution. In contrast to Segoviano (2006), we utilize a dynamic variance-covariance matrix by estimating a unique variance-covariance matrix at each point in time using the one-year rolling period correlation coefficients between the daily changes in the five-year CDS spreads of sovereign and

\footnotetext{
${ }^{5}$ Note that we do not include the positivity constraint, $p\left(x_{1}, x_{2}, \cdots, x_{n}\right) \geq 0$, since we explicitly assume the prior is a non-negative function.

${ }^{6}$ We pool banks and sovereigns together based on their marginal probabilities of default and not based on their CDS spreads. Indeed, treating banks and sovereign equally based on their CDS spreads is counterintuitive, since their reference entities are two different types of economic entities, public and private. However, the unique setup of the CIMDO procedure allows us to form one multivariate system consisting of both banks and sovereigns. To see this, assume that the system's joint probability distribution is unknown but each entity's marginal probability of default is known. To recover the underlying joint probability distribution of the system, the CIMDO procedure pools together each entity's marginal probability of default and utilizes the CIMDO copula to derive the underlying dependence structure of the system, which is consistent with the marginal probabilities of default. As a result, allowing banks and sovereigns to appear simultaneously in equation (4) based on marginal probabilities of default is not problematic.
} 
bank CDS contracts. ${ }^{7}$ The reason for using a dynamic variance-covariance matrix is because, at a given point in time, the CoJPoD should only reflect information that is available at that time. We use a correlation structure based on risk, that is, CDS spreads, rather than one based on asset value, because the CIMDO procedure uses the marginal probabilities of default to proxy for the underlying asset process of the system, which then automatically updates the CIMDO copula whenever there are changes in individual probabilities of default. Therefore, the correct correlation structure to use when solving for the unknown posterior distribution is one that is based on risk rather than on asset value. ${ }^{8}$

To solve for the posterior distribution, Radev (2013) numerically solves the optimization problem in equation (5). While this numerical optimization procedure works well for lower dimensions, it suffers from the curse of dimensionality once there are more entities in the system. Our study requires CoJPoD to be estimated for systems containing up to 54 entities consisting of both sovereigns and banks. Thus, to estimate CoJPoD in higher dimensions, we utilize the generalized cross-entropy (GCE) method (Botev \& Kroese, 2011) to solve for the posterior distribution. We show that consistent estimators for the Lagrange multipliers required in equation (6) can be obtained by numerically solving the following set of non-linear equations (see Appendix A for details):

$$
\frac{1}{n} \sum_{k=1}^{n}\left[\chi_{j}\left(\mathbf{x}_{k}\right) \exp \left(\sum_{i=0}^{n} \lambda_{i} \chi_{i}\left(\mathbf{x}_{k}\right)-1\right)\right]=P o D_{I_{j}}
$$

for $j=0,1, \cdots, n$, where $\left\{\mathbf{X}_{k}\right\}_{k=1}^{n} \sim q, \chi_{0}(\cdot)=1$, and $P o D_{I_{0}}=1$.

Since the posterior distribution is updated daily, this implies that CoJPoD is also updated daily. Therefore, CoJPoD is neither an ex ante nor an ex post measure of systemic risk but, rather, a contemporaneous measure. As mentioned by Bisias et al. (2012), measuring systemic risk is not simply a matter of obtaining early warning signals for impending dangers; crisis response is also an important role for policymakers who are charged with systemic risk monitoring. Thus, the usefulness of CoJPoD lies in its ability to help monitor the ongoing state of the system and the identification of failing institutions and markets. Furthermore, since CoJPoD can be updated on a daily basis, it can provide valuable real-time signals of fragility in an emerging crisis.

\subsection{Decomposition of the conditional joint probability of default}

The variable CoJPoD is a risk-neutral measure of systemic risk because its input, $P o D$, is derived from an arbitrage-free model. Hence, we can decompose the systemic risk into physical (or

\footnotetext{
${ }^{7}$ Segoviano (2006) uses a static variance-covariance matrix by estimating the sample correlation coefficients between the daily changes in the five-year CDS spreads of sovereign and bank CDS contracts from the whole sample.

${ }^{8}$ Gapen, Gray, Lim, and Xiao (2008) measure sovereign correlation structure by using the correlation coefficients between each sovereign's estimated logarithms of asset values. The authors show that their measure is highly correlated with the CDS spreads of the respective sovereigns.
} 
objective) probabilities of default and risk premium components. Exploring these two elements simultaneously allows us to determine which component of CoJPoD is the dominating factor throughout our sample period. Kim, Loretan, and Remolona (2010) purport that, during periods of high volatility, the risk premium components tend to dominate CDS spreads. Given that CDS spreads are the main ingredient for constructing $C o J P o D$, our aim is to investigate how much of the variation in CoJPoD is determined by changes in the pure credit quality of institutions and how much is induced by market risk perceptions.

We use the distance to default (DTD) metric to proxy for physical probabilities of default. In a banking context, the DTD measures how far away an institution is from default in units of standard deviation. A large DTD value implies that the institution is far from default and is deemed to have a low physical probability of default. We obtain data on the DTD from the website of the Risk Management Institute at the National University of Singapore. ${ }^{9}$ We use the DTD to proxy for physical default probabilities, since this metric is based solely on an institution's balance sheet items and therefore represents its pure credit quality.

Following Black, Correa, Huang, and Zhou (2013), we examine three prevalent risk premiums. First, we proxy for the default risk premium by computing the daily difference between the yields of 10-year euro zone industrials rated BBB and those rated AA+/AA (L. Chen, Collin-Dufresne, \& Goldstein, 2009). Second, we proxy for the liquidity risk premium by using the daily threemonth euro LIBOR/OIS (or EURIBOR/EONIA) spread (Brunnermeier, Crockett, Goodhart, Persaud, \& Shin, 2009). Third, we proxy for the sovereign risk premium by computing the daily difference between Germany's 10-year generic yield and the average of the Spanish and Italian 10-year generic yields weighted by their quarterly real gross domestic products (GDPs). An important caveat is that EA governments and other international bodies often provide bailout packages and guarantees for the European banking system; consequently, senior CDS spreads will be adjusted downwards. Therefore, in our subsequent empirical analyses, marginal contributions from physical probabilities of default and risk premiums should be interpreted as lower bounds in the case of no government support.

\section{Data}

In July 2011, the EBA released the results of their stress tests for a broad range of 90 European banks from various countries around Europe, including Austria, Belgium, Denmark, France, Germany, Greece, Ireland, Italy, Norway, the Netherlands, Portugal, Spain, Sweden, and the United Kingdom. This group of banks and sovereigns forms the starting point of our sample. We select banks and sovereigns based on liquidity criteria to ensure that CDS spreads reflect meaningful information on bank and sovereign credit risk. Specifically, each bank and sovereign must have informative CDS contracts for maturities of one to five years for the period 1 January 2008 to 31 December 2013. A CDS contract is informative during a certain quarter if at least

\footnotetext{
${ }^{9}$ The data can be accessed at http://rmicri.org.
} 
$70 \%$ of its spread changes are non-zero during the quarter. We do not include banks or sovereigns that have non-informative CDS contracts. Our sovereign sample consists of all 14 sovereigns used in the EBA stress test, which can be decomposed as follows. We include 10 EA sovereigns, five of which are peripheral sovereigns (Greece, Ireland, Italy, Portugal, and Spain) and the remaining are core sovereigns (Austria, Belgium, France, Germany, and the Netherlands). We also include three European Union (EU) sovereigns (Denmark, Sweden, and the United Kingdom), since their economies play a big role in the stability of the EA. Finally, we include Norway, which is part of neither the EA nor the EU but is closely associated with the EU through its membership in the European Economic Area. Our bank sample consists of 40 banks out of the 90 used in the EBA stress test. We include banks with informative CDS contracts from all 14 sovereigns, with the exception of Norway, which does not have any banks with informative CDS contracts. In addition, we include banks from Switzerland but do not use Switzerland in our sovereign sample since its sovereign CDS contract is not informative enough for the majority of our sample period. Table 1 gives an overview of the banks and sovereigns used in our study.

Our sample period is from 1 January 2008 to 31 December 2013, allowing us to compare the level of systemic risk from the 2008 global financial crisis through to the recent European sovereign debt crisis. The beginning of the sample period is dictated by the availability of informative CDS data for all sovereigns and banks in the study. To avoid any ambiguity regarding the period of these two crises, we follow Arghyrou and Kontonikas (2012) and define the global financial crisis as the start of our sample period to April 2009 and the sovereign debt crisis from January 2011 to July 2012. The start date of the sovereign debt crisis coincides with the expansion of the capital guarantee of the European Financial Stability Facility (EFSF). We use USD-denominated (EUR-denominated) senior CDS contracts with maturities of one to five years for sovereigns (banks). Daily CDS mid-rate spreads are obtained from CMA, Datastream. Following prior literature, we use USD-denominated CDS contracts for sovereigns, since they are considerably more liquid than their EUR-denominated counterparts (e.g., Lucas et al., 2014; Radev, 2013).

With regards to our bootstrapping procedure, we proxy for discount rates by using the daily AAA EA government bond yields with maturities of three months to five years, obtained from the ECB's Statistical Data Warehouse. As part of the CIMDO procedure, we proxy for the sovereign correlation matrix by calculating a unique variance-covariance matrix at each point in time using the one-year rolling period correlation coefficients between the daily changes in the five-year CDS spreads of the sovereigns in our sample. The correlation structure of the banking system and the combined sovereign and banking system is calculated similarly. We choose a maturity of five years, since these CDS contracts are the most liquid and most actively traded contracts on the market. We summarize the information contained in the dynamic variance-covariance matrices for sovereigns by presenting the sample average sovereign correlation matrix in Table 2 . For the decomposition of systemic risk, the data used to construct the default risk premium, the liquidity risk premium, and the sovereign risk premium are all obtained from Bloomberg. 


\section{Empirical results}

Our empirical analyses are organized as follows. First, we apply the methodology outlined in Section 2 to estimate the perceived level of systemic risk in the European sovereign system. We then investigate the systemic risk within the peripheral sovereigns and the systemic impact of peripheral sovereigns on the core sovereigns. Next, we explore the systemic risk of the European banking system and attempt to uncover the most systemically risky banks as perceived by market participants. We then combine the sovereign and banking systems and examine the systemic risk in this multivariate system on dates of major events. Lastly, we study the decomposition of systemic risk into physical probabilities of default and risk premium components.

\subsection{Systemic risk in the European sovereign system}

We begin by investigating the two key ingredients of the CoJPoD measure, PoD and JPoD. Figure 1 presents the bootstrapped probabilities of default for the 14 sovereigns (split into the core, peripheral, and non-EA sovereign systems in panels (a), (b), and (c), respectively) and the joint probability of default for the sovereign system (panel (d)). On average, peripheral sovereigns were perceived by investors to be the most likely to default, with Ireland and Portugal reaching probabilities of default of almost $20 \%$ in July 2011. At the extreme, the probability of default of Greece reached a plateau of $100 \%$ towards the end of our sample period due to the CDS credit event triggered for Greece in March 2012. On the other hand, core sovereigns such as Germany and the Netherlands were highly unlikely to default throughout the entire sample period. Similarly, non-EA sovereigns such as Norway, Sweden, and the United Kingdom were largely unaffected by the sovereign debt crisis. In panel (d), we see that the joint probability of default of the sovereign system was at its peak during the sovereign debt crisis. Taken together, our results imply that the divergence in market expectations around individual sovereign defaults may not only be due to the inability of individual sovereigns to service their debts, but also be about the potential of the EA as a whole to support its members in need.

Figure 2 presents the conditional joint probability of default of the sovereign system given the default of each sovereign in our sample. The sovereign that defaults is indicated in the legend of each panel. Comparison of panels (a) and (b) during the sovereign debt crisis illustrates the disparity between the perceived systemic risk of core sovereigns defaulting and that of peripheral sovereigns defaulting. For example, in November 2011, the CoJPoD value of the sovereign system reached $47 \%$ given the default of Germany, whereas the default of the larger peripheral sovereigns, such as Italy and Spain, produced CoJPoD values of only $30 \%$. This finding implies that market participants perceive core sovereigns to be the safest sovereigns, whose defaults have severe consequences on the sovereign system. In contrast, the default of peripheral sovereigns is perceived to be less influential on the sovereign system, which reflects the lower investor confidence in peripheral sovereigns. Panel (c) shows that non-EA sovereigns are critical in maintaining the stability of the EA. Evidently, during the sovereign debt crisis, 
the stable AAA ratings of Denmark and Sweden attracted many investors who were seeking to diversify away credit risk from the troubled peripheral sovereigns. In addition, the public debt loads of Sweden and Denmark were far below the EA average. Thus, market participants perceived non-EA sovereign defaults as negative credit events with significant systemic risk spillover to the entire sovereign system. Although these results confirm macroeconomic intuition, the benefit of our approach is that we are able to quantify probabilistically the perceived level of systemic risk given a sovereign default.

We now interchange the order of conditioning and calculate the conditional joint probability of default of a particular sovereign given the default of the sovereign system excluding that sovereign. This process will reveal the resilience of each sovereign to system-wide sovereign defaults. Figure 3 presents the results. In panel (b), during the sovereign debt crisis, we observe that peripheral sovereigns are the least resilient to the default of the sovereign system. From late 2011 onwards, Greece, Italy, Portugal, and Spain are guaranteed to default given the default of the sovereign system. In contrast, the resilience of Ireland improves dramatically towards the end of our sample period. The weak resilience of peripheral sovereigns during the height of the sovereign debt crisis is most likely a result of their dependence on other EA states for bailout funds. Therefore, if negative events occur in the rest of the sovereign system, market perceptions indicate that serious repercussions would follow for the peripheral sovereigns.

In panel (a) of Figure 3, we see that, among the core sovereigns, Germany and the Netherlands are highly resilient to systemic default risk, reinforcing their pivotal role in maintaining the stability of the EA. Taken together with the results in panel (a) of Figure 2, our findings indicate that market participants perceive Germany and the Netherlands as anchors of stability within the EA. Thus, if these sovereigns were to default, then the entire sovereign system would collapse. This finding is not surprising, given that Germany is one of the largest contributors to the bailout packages provided to fiscally weak peripheral sovereigns such as Greece. Among the non-EA sovereigns in panel (c) of Figure 3, we observe that Sweden and Norway are two of the most resilient to systemic default risk. This is expected, because neither sovereign is part of the EA and investors perceived the government bond markets of both sovereigns to be safe havens during the sovereign debt crisis.

\subsection{Systemic impact of peripheral sovereigns}

In the preceding section, we show that the peripheral sovereigns were the least resilient to systemic default risk. Recent literature provides evidence that peripheral sovereigns are the main source of instability in the EA (e.g., Aizenman, Hutchison, \& Jinjarak, 2013; Arghyrou \& Kontonikas, 2012; Beirne \& Fratzscher, 2013; Black et al., 2013; De Santis, 2012; Gorea \& Radev, 2014). Given the interdependence between peripheral and core sovereigns, we now focus on the systemic risk within the peripheral sovereigns and potential systemic risk spillover between the peripheral and core sovereigns. 
Within the peripheral sovereign system, we are especially concerned with the perceived systemic risk spillover between the smaller sovereigns (Greece, Ireland, and Portugal) and the larger economies (Italy and Spain). Figure 4 presents the conditional joint probability of default of each peripheral sovereign given the default of other peripherals listed in the legend of each panel. In panel (a), we see that, within the peripheral sovereign system, Greece's fiscal stability is perceived to be largely dependent on that of Ireland and Portugal, especially towards the end of our sample period, when the CoJPoD value of Greece given the joint default of Ireland and Portugal reached $77 \%$. In panels (b) and (d), we observe the perceived importance of the larger peripheral sovereigns (Italy and Spain) in maintaining the stability of Ireland and Portugal during the height of the sovereign debt crisis. Panels (c) and (e) show that Italy and Spain are highly interdependent sovereigns. Specifically, the CoJPoD value of Italy (Spain) given the default of Spain (Italy) is consistently greater than that given the joint default of Greece, Ireland, Portugal, and Spain (Italy). ${ }^{10}$ The results in Figure 4 not only emphasize the potential systemic risk spillover effects between peripheral sovereigns but also reinforce the perceived stabilization role that the large peripheral sovereigns Italy and Spain play in the peripheral sovereign system.

We now investigate potential systemic risk spillover effects between the peripheral sovereigns and the rest of the sovereign system. Figure 5 presents the conditional joint probability of default of the rest of the sovereign system given the joint default of two, three, four, and all five peripheral sovereigns, respectively. Across all panels, we see that different combinations of peripheral sovereign defaults are perceived to have different levels of systemic risk spillover on the rest of the sovereign system. When two peripheral sovereigns jointly default (panel (a)), credit market participants seem to be most concerned with the potential joint default of Italy and Spain. Panels (b) and (c) show that the default of Ireland, Italy, and Spain and the default of Ireland, Italy, Portugal, and Spain, respectively, have the greatest destabilizing effects on the perceived default vulnerability of the sovereign system. The high level of cross-sectional heterogeneity in the perceived systemic impact when different peripheral sovereigns default implies that regulators should take into account not only the size of peripheral sovereign defaults but also which combinations of peripheral sovereigns default.

The results from Figures 4 and 5 also reflect credit events that unfolded during the sovereign debt crisis. On May 2010, the EFSF was established to provide financial assistance to EA member states experiencing financing difficulties. The facility had a lending capacity of 440 billion euros that could be combined with loans of up to 250 billion euros from the International Monetary Fund (IMF). As of December 2013, Eurostat data reported the public debt of Ireland and Portugal to be 203 billion euros and 214 billion euros, respectively. Therefore, any potential systemic risk spillover of smaller peripheral sovereigns could be dissolved by financial stabilization mechanisms. In contrast, the combined public debt of Italy and Spain far exceeded the lending capabilities of the EFSF. This is one of the reasons why, in panel (a) of Figure 5, the joint default

\footnotetext{
${ }^{10}$ Indeed, Table 2 shows that the average correlation between Italy and Spain is 0.85 , whereas the average correlation between Italy and Greece, Ireland, Portugal, and Spain is much lower, 0.53.
} 
of Italy and Spain produced the highest $C o J P o D$ value during the height of the sovereign debt crisis.

\subsection{Systemic risk in the European banking system}

We now shift our attention to the systemic risk of the European banking system. We first examine the systemic risk contributions of banks at the country level and then at the individual bank level. Figure 6 presents the conditional joint probability of default of the banking system given the joint default of all banks in each sovereign listed in the legend of each panel. In panel (a), we see that, among the core sovereigns, the banks perceived by market participants to be the most interdependent with the European banking system were those in France. During the height of the sovereign debt crisis, the potential systemic risk spillover effects of French banks intensified dramatically as the value of CoJPoD peaked at $34 \%$. This result is consistent with the fact that, during 2011-2012, French banks suffered greatly from decreasing levels of capital and reduced lending from short-term investors. Such deterioration in traditional banking operations led to a downgrade in the debt of major French banks such as BNP Paribas, Société Générale, and Crédit Agricole. Consequently, investors feared that the collapse of French banks would plunge Europe into a full-blown banking crisis. According to panel (b), banks in the large peripheral sovereigns such as Italy and Spain were perceived to be the most systemically risky, which is indicative of their local risk concentration and their increased holdings of sovereign debt. Panel (c) shows that non-EA banks in the United Kingdom and Switzerland also play a role in maintaining the stability of the European banking system, consistent with the notion that market participants consider the solvency of non-EA banks a pillar of support for the rest of the financial system. The findings in Figure 6 are in line with those of Betz et al. (2015), who also find that the most interconnected banks are from France and Spain.

We now investigate the systemic risk contribution of banks at the individual bank level. Table 3 presents the conditional joint probability of default of the banking system given the default of individual banks on five dates: (i) 15 September 2008, the day Lehman Brothers filed for bankruptcy; (ii) 10 March 2009, the date of the highest CoJPoD value during the global financial crisis for the panels in Figure 6; (iii) 2 May 2010, when Greece accepted the 110 billion euro EU-IMF loan package; (iv) 25 November 2011, the date of the highest CoJPoD value during the sovereign debt crisis for the panels in Figure 6; and (v) 19 December 2013, the date of the lowest CoJPoD value at the end of our sample period for the panels in Figure 6. As a measure of bank size during the sovereign debt crisis, the last two columns present the total assets and total liabilities in 2011 of each bank in billions of euros.

The most immediate observation is that the biggest contributors to the systemic risk of the banking system often coincide with the biggest banks originating from the sovereign. For example, the CoJPoD of the banking system given the default of the biggest bank in Spain, Banco Santander SA, was $32.5 \%$ on 25 November 2011. This value is much larger than the 
CoJPoD given the default of the smallest bank in Spain, Banco de Sabadell SA, which was only $19.5 \%$ on the same date. The systemic risk contribution of Banco Santander SA is almost identical in magnitude to that of Deutsche Bank AG, which attained a CoJPoD value of $32.2 \%$ on 25 November 2011. Our results suggest that bank size and interdependence are crucial factors in determining the perceived systemic risk of individual banks, which is in line with Tarashev, Borio, and Tsatsaronis (2009). Another observation is that, while Figure 6 shows that the joint default of French banks contributed the most to the systemic risk during the global financial crisis and the sovereign debt crisis, Table 3 shows that individual defaults of French banks are perceived to be just as systemically risky. For example, the CoJPoD values on 10 March 2009 and 25 November 2011 corresponding to the three largest French banks-BNP Paribas, Société Générale, and Crédit Agricole - are substantially larger than almost all the other CoJPoD values on the same dates. Our results are consistent with those of Betz et al. (2015), who also identify these three French banks as among the most strongly interconnected banks in the European financial system.

\subsection{Systemic risk in the combined European sovereign and banking system}

Up until now, our focus has been on the sovereign system and banking system in isolation. We now consider sovereigns and banks as entities of an entire system and examine the evolution of systemic risk in this multivariate system. We choose sovereigns to be the trigger of default and examine their systemic impact on the banking system. Figure 7 presents the time-varying dynamics of the CoJPoD of the banking system given the default of a core sovereign (Germany), a peripheral sovereign (Italy), and a non-EA sovereign (United Kingdom).

The systemic risk was lowest at the beginning of our sample period (panel (a) of Figure 7) but began to climb steadily as market participants expected negative shocks from the United States to spill over into the European banking sector. The first peak occurred on 14 March 2008, when the Federal Reserve and JP Morgan bailed out Bear Stearns. However, this episode was quickly defused due to rapid interventions by the Federal Reserve. The first major systemic shock to the European banking system occurred on 15 September 2008, when Lehman Brothers filed for bankruptcy. A period of recovery followed, as the G20 Summit vowed to boost growth and prevent future crises. However, this pledge was short-lived, as the CoJPoD given the default of Germany peaked at 21\% on 10 March 2009, coinciding with the Dow Jones Industrial Average slumping to an all-time low. Indeed, the significant rise in CoJPoD shows that European banks were not spared the after-effects of such events. It was not until 2 April 2009, when the G20 set up the Financial Stability Board, that global financial markets began to calm down.

The evolution of CoJPoD throughout the sovereign debt crisis was mostly a result of credit events spawned within the EA (panel (b) of Figure 7) rather than external shocks from the United States. The CoJPoD value increased sharply on 2 May 2010, when Greece signed a loan package of 110 billion euros with the EU and IMF. The release of the 2010 round of banking 
stress tests on 23 July 2010 revealed that banks were likely to suffer losses on their sovereign debt exposures given a negative sovereign shock. Consistent with the stress test results, the CoJPoD of the banking system given a sovereign default maintained an upward trend. The release of the 2011 round of banking stress tests on 15 July 2011 marked a new period of heightened systemic risk in the EA. This round of stress test results revealed that banks in peripheral sovereigns were unlikely to weather negative sovereign shocks. The negative outlook was further reinforced at the G20 Summit on 14 October 2011, when concerns were raised regarding the possible financial contagion of a Greek default spreading to core sovereigns and accelerating the fiscal distress of peripheral sovereigns. The CoJPoD measure successfully captures this negative information as it reached an all-time high on 30 November 2011. To sum up, our findings indicate that major events during the global financial crisis and the European sovereign debt crisis had a strong impact on the perceived systemic risk of the European sovereign and banking system.

\subsection{Decomposition of systemic risk}

As mentioned in Section 2.4, CoJPoD is a risk-neutral measure of systemic risk that incorporates information not only on physical default risk but also on risk premium components such as the liquidity risk premium, the default risk premium, and the sovereign risk premium. Our aim is to decompose the systemic risk of the combined sovereign and banking system and determine how much of its movement is induced by changes in the physical default loss of banks and how much is steered by changes in market sentiments (change in perceptions towards liquidity risk, default risk, and sovereign risk). To achieve this, we use the conditional joint probability of default of the sovereign system given the joint default of all banks within a particular sovereign as our measure of systemic risk. We choose banks to be the trigger of default because the DTD is a measure of physical default risk for banks only. Thus, by conditioning on the default of banks, we allow the systemic risk of the sovereign system to be influenced by the physical probabilities of default of banks.

In Figure 8, panels (a), (c), and (e) present the conditional joint probability of default of the sovereign system, given the joint default of all banks in each sovereign (listed in the legend of each panel) in the core, peripheral, and non-EA sovereign systems, respectively. Panels (b), (d), and (f) present the average DTD of all banks in each sovereign (listed in the legend of each panel) in the core, peripheral, and non-EA sovereign systems, respectively. ${ }^{11}$ The time-varying nature of the CoJPoD values in panels (a), (c), and (e) provides evidence that the dynamics of the negative feedback loops between the European sovereign and banking systems are driven by systemic externalities originating from the banking sector, which, in turn, negatively impacts the fiscal positions of sovereigns. Comparing panels (a) and (c), we see that, during the global financial crisis in 2009, the average CoJPoD value corresponding to the joint default of banks in core sovereigns peaked at $10.12 \%$, compared to only $6.62 \%$ for peripheral sovereigns. However,

\footnotetext{
${ }^{11}$ The sample period is from 1 January 2008 to 1 July 2013 because DTD data are available only up to 1 July 2013
} 
during the height of the sovereign debt crisis in 2011, the average CoJPoD value corresponding to the joint default of banks in peripheral sovereigns increased by $8.91 \%$, whereas that of core sovereigns increased by only $6.22 \%$. These results indicate that, during the sovereign debt crisis, market participants perceived the systemic linkages between sovereigns and banks to be stronger for peripheral sovereigns than for core sovereigns. Similarly, Betz et al. (2015) show that sovereign-bank linkages for crisis countries (i.e., Ireland, Italy, Portugal, and Spain) were lower than those of non-crisis countries during the global financial crisis. However, the strength of sovereign-bank linkages for crisis countries increased with the progression of the sovereign debt crisis.

In panels (b), (d) and (f) of Figure 8, we see that, from the beginning of our sample to 10 March 2009 (the first major peak in the CoJPoD series during the global financial crisis), CoJPoD and the DTD are moving in opposite directions. Since a lower DTD means that a bank is closer to default, this negative relation between the two series implies that increases in the systemic risk of the sovereign system were mostly a result of the increased physical default risk of banks during the global financial crisis. Since the beginning of the sovereign debt crisis, CoJPoD and the DTD maintain a very strong negative relation in peripheral sovereigns such as Italy, Portugal, and Spain. In contrast, CoJPoD and the DTD share a positive relation in core sovereigns such as Austria, France, and Germany and in non-EA sovereigns such as Denmark, Sweden, Switzerland, and the United Kingdom. These results suggest that the physical stress placed on banks in peripheral sovereigns is the main contributor to the systemic risk of the sovereign system. Indeed, the sovereign debt crisis is a crisis of European origin; thus, the pure credit quality of banks in peripheral sovereigns is likely to be of much greater importance, given their large exposures to sovereign debt. Furthermore, deterioration of the real economy placed immense pressure on the European banking system, generating substantial downward revisions in the credit quality of banks in peripheral sovereigns. On the other hand, the physical condition of banks in non-peripheral sovereigns has been improving, as indicated by increasing values of DTD. Therefore, for banks in non-peripheral sovereigns, systemic risk is primarily driven by risk premiums.

We now take the analysis a step further and use regression analysis to examine the impact of physical default risk and risk premium components on the systemic risk of the sovereign system. The dependent variable in our panel regression is the conditional joint probability of default of the sovereign system given the joint default of all banks in a particular sovereign (denoted CoJPoD for short). We include three state variables to control for common risk factors. To control for market-wide credit risk, we include the European iTraxx index (Itraxx), which is an equally weighted index of the 125 most liquid CDS series in the European market. A higher iTraxx index value signals a higher overall credit risk in the economy; therefore, we expect a positive relation between the iTraxx index and CoJPoD. The second variable we include is the 24-month Vstoxx volatility index (Vstoxx). The Vstoxx index reflects the market perceptions of short-term volatility in Europe; therefore, increases in the Vstoxx index signify uncertainty 
regarding the strength of economic fundamentals of European sovereigns. We predict a positive relation between the Vstoxx index and CoJPoD. Lastly, we include the Europe Datastream Market Index (Market) to control for market-wide business climate. We predict that improving economic prospects, signalled by increases in the market index, should decrease CoJPoD. All three variables are obtained from Datastream. Our main variables include the liquidity risk premium $(L R P)$, the default risk premium $(D R P)$, the sovereign risk premium $(S R P)$, and the DTD $(D T D)$. The specification can thus be written as follows:

$$
\operatorname{CoJPo}_{i, t}=\alpha+\beta \cdot \text { Risk Premium }_{t}+\gamma \cdot D T D_{i, t}+\phi \cdot X_{t}+\epsilon_{i, t}
$$

where Risk Premium $_{t}$ is the vector of risk premium variables, $D T D_{i, t}$ is the average DTD of all banks in sovereign $i$, and $X_{t}$ is the vector of control variables. In unreported tests, we find that most of our variables are non-stationary, which will yield spurious results when we run the regression in levels. To deal with this problem, we convert all variables into arithmetic returns. We run the regression using monthly observations from 1 January 2008 to 28 June 2013, since this is the frequency and period for which we have available DTD data.

Table 4 presents the results of the panel regression. Columns (1) to (3) include the risk premium variables individually, while column (4) includes the DTD individually. Column (5) uses all variables. Columns (6) and (7) use banks from peripheral and non-peripheral sovereigns, respectively. All columns employ sovereign fixed effects. We note that all three state variables have the expected signs and are significant across all columns. This result shows that the three state variables are successful in capturing sources of commonality and so we can be confident that the loadings on the risk premium variables and the DTD reflect the decomposition of systemic risk over and above what can be explained by fundamental factors. In columns (2) and (3), the coefficients of the default risk premium and the sovereign risk premium are both positive and highly significant, indicating that changes in market risk perceptions play an important role in driving the variation in the systemic risk of the sovereign system. Surprisingly, the coefficient of the liquidity risk premium is negative (column (1)), although marginally significant. The DTD has the expected negative coefficient (column (4)); however, its weak significance indicates that the effect of physical probabilities of default on the systemic risk of the full sample of sovereigns is not so clear-cut.

The multivariate joint regression in column (5) of Table 4 further reinforces the importance of risk premium components in driving up systemic risk as the coefficients of the default risk premium and sovereign risk premium continue to be positive and highly significant. Unexpectedly, the loading on the liquidity risk premium remains negative and actually increases in significance. One possible explanation for this result is the implementation of policies that were aimed at injecting liquidity into the banking system and relieving the financing troubles of European banks, for example, the Federal Reserve's dollar liquidity swap with the ECB in November 2011 and the ECB's long-term refinancing operations in December 2011. During the sovereign debt 
crisis, these interventions were not just a one-time occurrence; rather, market interventions became the new normal. Thus, in this self-validating cycle of rescue packages, liquidity dry-ups could be a signal of market intervention that subsequently decreases the systemic risk. Finally, the DTD is still negatively related to the systemic risk of the sovereign system; however, it is only significant at the $10 \%$ level, suggesting that physical default risk has confounding effects on banks in peripheral and non-peripheral sovereigns. Consistent with the observation in Figure 8 that the negative association between the DTD and the CoJPoD is stronger for banks in peripheral sovereigns, when we restrict our sample of banks to only those in the peripheral sovereigns, the coefficient of the DTD variable increases in significance while the sovereign risk premium decreases in significance (column (6)). This result supports the notion that physical probabilities of default play a larger role in determining the level of systemic risk for banks in peripheral sovereigns. In contrast, Figure 8 also appears to suggest that it is mainly the risk premium components that induce increases in systemic risk for banks in non-peripheral sovereigns. We can confirm this observation, since column (7) shows that when we restrict our sample of banks to those in non-peripheral sovereigns, the DTD variable becomes insignificant while the sovereign risk premium increases in significance.

\subsection{Robustness tests}

In this section, we show that our main findings are robust to using alternative model estimations in calculating the CoJPoD of various systems and to different regression specifications in examining the decomposition of systemic risk. In addition, we use alternative measures of systemic risk such as the marginal expected shortfall (MES) to illustrate the robustness of our estimation methodology. In specifying alternative model estimations, we use data beginning in 2007 to not only provide more comparability to the analysis through the crisis periods but also improve the dynamic dependence structure of the CIMDO procedure by adding an extra year of lag in the estimation of the dynamic variance-covariance matrix.

We start by repeating the analysis in Figures 2 and 4 by excluding Greece from the system. Greece is a clear outlier, given that it has the highest marginal probabilities of default (panel (b) of Figure 1) and the lowest CoJPoD values (panel (b) of Figure 2) and is the least resilient to system-wide sovereign defaults (panel (b) of Figure 3). Thus, removing Greece from the sovereign system allows us to check the sensitivity of our main results to potential outliers. Figure 9 presents the conditional joint probability of default of the sovereign system excluding Greece, given the default of a particular sovereign. The time variation in the CoJPoD values across all panels mirrors that in Figure 2 up until March 2012, after which there is a sizable decrease in all of the CoJPoD series. This result is expected, since a CDS credit event was triggered in March 2012 that resulted in Greece's default. Hence, removing a sovereign that has already defaulted from the sovereign system should theoretically lead to lower CoJPoD values, which our results indicate after March 2012. 
Figure 10 presents the conditional joint probability of default of a particular peripheral sovereign given the default of other peripheral sovereigns, excluding Greece. Prior to March 2012, all CoJPoD series increased compared to that in Figure 4, consistent with the interpretation that, after the removal of Greece, the systemic default risk within the peripheral sovereign system has increased. Examining Table 2 shows that Greece is the least interdependent sovereign within the peripheral sovereign system, since the average correlation between Greece and the other peripheral sovereigns - Ireland, Italy, Portugal, and Spain - is considerably lower than the correlation between the other peripheral sovereigns themselves. Consequently, the exclusion of Greece increases the CoJPoD value of the remaining peripheral sovereigns since they are more interdependent with each other. However, after March 2012, there is a decrease in all of the CoJPoD series, since Greece's default has been removed from the peripheral sovereign system.

Next, we re-examine the systemic impact of peripheral sovereigns on the entire sovereign system by removing Ireland from the analysis conducted in Figure 5. As shown in panel (b) of Figure 3, Ireland's peak crisis occurred earlier relative to the other peripheral sovereigns and its recovery starting in mid-2012 was significantly better than that of all the other peripheral sovereigns. Thus, including Ireland along with the other peripheral sovereigns could mask the latter's role when examining the potential systemic risk spillover between peripheral sovereigns and the rest of the sovereign system. Since we are mainly concerned with the joint default of multiple peripheral sovereigns, Figure 11 presents the conditional joint probability of default of the sovereign system given the joint default of three or four peripheral sovereigns, excluding Ireland. Compared with panel (c) of Figure 5, both panels in Figure 11 show that, when Ireland is removed, the CoJPoD value of the remaining sovereigns decreases, most notably after November 2012. This result is expected, since, of all the peripheral sovereigns, market participants had the most confidence in Ireland, given its rapid recovery during this period. Thus, if Ireland were to default, it would trigger systemic shocks to the other peripheral sovereigns, increasing the CoJPoD of the sovereign system. Naturally, Ireland's removal from the peripheral sovereign system means that investors do not have to consider this possibility, which leads to a lower value of CoJPoD.

To provide evidence that our main results are not driven by our choice of estimation methodology, we use the MES to re-evaluate the systemic risk in the European banking system previously examined in Figure 6. Following Acharya, Engle, and Richardson (2012), a bank's MES can be interpreted as reflecting its contribution to the banking system's overall systemic risk. The reasons for our choice in using the MES as a comparable measure of systemic risk are threefold. First, the MES is a popular and readily available measure of systemic risk used in the banking sector, a setting in which the CoJPoD is also applicable. Second, it has been shown that MES is successful in tracking episodes of financial turmoil, which makes it a real-time indicator, just like CoJPoD, when monitoring the systemic risk of the European banking system (Idier, Lamé, \& Mésonnier, 2014). Third, Drehmann and Tarashev (2011) show that the MES can be used to gauge future probabilities of default, which is one of the key components of CoJPoD. 
We follow the econometric methodology developed by Brownlees and Engle (2012) to estimate the dynamic MES on a monthly basis. ${ }^{12}$ A high MES value indicates a greater contribution to the banking system's overall systemic risk.

Figure 12 presents the average MES of all banks in a particular sovereign. Each MES series can be interpreted as the average contribution to the overall systemic risk of the European banking system by all of the banks originating from the sovereign listed in the legend of each panel. We see that the results based on the MES are similar to those based on using the CoJPoD when examining the dynamics of systemic risk in the European banking system. Within the core sovereigns, the MES identifies French banks as the most systemically risky, while, for the peripheral sovereigns, Italian and Spanish banks pose the most systemic risk. For non-EA sovereigns, banks in Switzerland and the United Kingdom appear to be the most systemically interconnected with the banking system. The rankings based on the MES are in line with those obtained using CoJPoD in Figure 6. The overall MES trend also coincides with the time variation of CoJPoD. In particular, we see two major peaks in each panel of Figure 12 corresponding to the global financial crisis in 2009-2010 and the European sovereign debt crisis in 2011-2012. Overall, the results obtained using the MES are consistent with those obtained using CoJPoD.

We now revisit the decomposition of systemic risk by using alternative regression specifications. First, we consider the scenario in which the global list of systemically important banks (GSIB) is removed from our sample. Since the impact of banks' physical default risk is concerned with the proper estimation of their individual role in the banking system, removing the banks in the GSIB from our sample can shed light on whether our results are driven by the most systemically risky banks. Second, we use an alternative measure of physical default risk by replacing the DTD with the SRISK measure introduced by Brownlees and Engle (2012). The SRISK measure can be interpreted as the expected capital shortage of a firm during a crisis and it is a function of firm leverage and MES. ${ }^{13}$ Third, we introduce two crisis dummies, one for the global financial crisis and one for the sovereign debt crisis, to account for the presence of instabilities not captured by the main variables or the control variables. The two sets of dummy variables are also interacted with the risk premium variables and the DTD to examine whether their contribution changes between the two crisis periods. Table 5 presents the results of the alternative specifications for the decomposition of systemic risk.

Columns (1) to (3) of Table 5 presents the regression results with the exclusion of the GSIB. When using the full sample of banks, the coefficients of the risk premium variables are consistent with those in column (5) of Table 4. However, the DTD becomes insignificant, implying that the credit quality of the GSIB banks contributes to a degree to the banking system's systemic

\footnotetext{
${ }^{12}$ Brownlees and Engle (2012) propose a multi-step modelling approach based on GARCH, dynamic conditional correlations, and non-parametric tail estimators. In our analysis, we use a loss threshold of $-2 \%$ and a bandwidth parameter of $5 \%$.

${ }^{13}$ As for the MES, we follow the dynamic modelling procedure of Brownlees and Engle's (2012) to estimate SRISK.
} 
risk. Columns (2) and (3) show that physical default risk is an important driver of systemic risk in the peripheral sovereign system but has no significant role in the non-peripheral sovereign system, which is in line with the sovereign subsample results in Table 4. Using SRISK in place of the DTD in columns (4) to (6) yields similar results. Since a higher value of SRISK is associated with greater capital shortages in the event of a crisis, the significantly positive coefficient of the SRISK variable in column (5) shows that deterioration in the physical condition of banks in peripheral sovereigns is an important determinant of systemic risk in the peripheral sovereign system.

Columns (7) and (8) of Table 5 show that, when crisis dummies are included, the systemic risk contribution of the risk premium components changes between the global financial crisis and the sovereign debt crisis. For instance, the significantly positive coefficient of the $D R P \times$ GFC dummy interaction across the two subsamples show that the default risk premium was the main determinant of systemic risk during the global financial crisis. In contrast, the sovereign risk premium was the dominant factor in driving systemic risk during the sovereign debt crisis, as shown by the significantly positive coefficient of the $S R P \times G F C$ dummy interaction. This result is consistent with the fact that the European sovereign debt crisis was characterized by an environment of overly high government deficits and accelerating sovereign debt levels. Thus, market perceptions related to sovereign credit risk differentials were responsible in driving systemic risk. Finally, the significantly negative coefficient of the DTD in column (7) emphasizes the systemic importance of physical default risk in the peripheral sovereign system.

\section{Conclusion}

This paper uses the conditional joint probability of default introduced by Radev (2013) to study the systemic risk of the European sovereign and banking system during the global financial crisis and the sovereign debt crisis. Although there is a significant amount of literature on sovereign and bank credit risk in isolation, there has been relatively little work in attempting to estimate the perceived level of systemic risk between the two. This paper contributes to the topic by incorporating individual default risk characteristics combined with joint default risk dynamics to estimate a probabilistic measure of systemic risk that is applicable in high dimensions. In addition, we fully exploit the conditional flexibility in the systemic risk measure by first investigating the levels of systemic risk in the sovereign and banking systems separately and then in the combined sovereign and banking system.

In our empirical applications, we compute a range of conditional probabilities for both the European sovereign and banking systems. The results indicate that significant time variations in systemic risk and major events during the global financial crisis and the European sovereign debt crisis had a strong impact on the perceived conditional default risk of the sovereign and banking system. We also condition on the default of banks and examine the decomposition of the systemic risk of the sovereign system. Our results show that the default risk premium 
and the sovereign risk premium played a major role in driving the variation in systemic risk. In addition, we show that the physical probability of default is also a significant component of systemic risk, especially for banks in peripheral sovereigns. 


\section{References}

Acharya, V., Engle, R., \& Richardson, M. (2012). "Capital shortfall: A new approach to ranking and regulating systemic risks". American Economic Review, 102(3), 59-64.

Acharya, V., Pedersen, L., Philippon, T., \& Richardson, M. (2010). "Measuring systemic risk". Working Paper, NYU Stern School of Business.

Adrian, T., \& Brunnermeier, M. (2011). "CoVaR". NBER Working paper No. 17454.

Aizenman, J., Hutchison, M., \& Jinjarak, Y. (2013). "What is the risk of European sovereign debt defaults? Fiscal space, CDS spreads and market pricing of risk". Journal of International Money and Finance, 34(1), 37-59.

Arghyrou, M., \& Kontonikas, A. (2012). "The EMU sovereign-debt crisis: fundamentals, expectations and contagion". Journal of International Financial Markets, Institutions 8 Money, 22(4), 658-677.

Avesani, R., Pascual, A., \& Li, A. (2006). "A new risk indicator and stress testing tool: a multifactor nth-to-default CDS basket". IMF Working Paper No. 06/105.

Bams, D., \& Wielhouwer, J. (2000). "Empirical issues in value at risk estimation: time varying volatility, fat tails and parameter uncertainty". Working Paper, Tilburg University.

Beirne, J., \& Fratzscher, M. (2013). "The pricing of sovereign risk and contagion during the European sovereign debt crisis". Journal of International Money and Finance, 34(1), $60-82$.

Betz, F., Hautsch, N., Peltonen, T. A., \& Schienle, M. (2015). "Systemic risk spillovers in the European banking and sovereign network". Journal of Financial Stability.

Billio, M., Getmansky, M., Lo, A., \& Pelizzon, L. (2012). "Econometric measures of connectedness and systemic risk in the finance and insurance sectors". Journal of Financial Economics, $104(3), 535-559$.

Bisias, D., Flood, M., Lo, A., \& Valavanis, S. (2012). "A survey of systemic risk analytics". Annual Review of Financial Economics, 4(1), 255-296.

Black, L., Correa, R., Huang, X., \& Zhou, H. (2013). "The systemic risk of European banks during the financial and sovereign debt crisis". International Finance Discussion Paper No. 1083.

Borwein, J., \& Lewis, A. (1991). "Duality relationships for entropy-like minimization problems". SIAM J. Control and Optimization, 29(2), 325-338.

Botev, Z., \& Kroese, D. (2011). "The generalized cross entropy method, with applications to probability density estimation". Methodology and Computing in Applied Probability, 13(1), $1-27$.

Brownlees, C., \& Engle, R. (2012). "Volatility, correlation and tails for systemic risk measurement". Working Paper, NYU Stern School of Business.

Brunnermeier, M., Crockett, A., Goodhart, C., Persaud, A., \& Shin, H. (2009). "The fundamental principles of financial regulations". Geneva Reports on the World Economy.

Bruyckere, V., Gerhardt, M., Schepens, G., \& Vennet, R. (2013). "Bank/sovereign risk spillovers in the European debt crisis". Journal of Banking and Finance, 37(12), 4793-4809.

Cai, J., Einmahl, J., Haan, L., \& Zhou, C. (2015). "Estimation of the marginal expected shortfall: the mean when a related variable is extreme". Journal of the Royal Statistical Society: Series B (Statistical Methodology), 7r(2), 417-442.

Chen, C., Iyengar, G., \& Moallemi, C. C. (2013). "An axiomatic approach to systemic risk". Management Science, 59(6), 1373-1388.

Chen, L., Collin-Dufresne, P., \& Goldstein, R. (2009). "On the relation between the credit spread puzzle and the equity premium puzzle". Review of Financial Studies, 22(9), 3367-3409.

Decarreau, A., Hilhorst, D., Lemarechal, C., \& Navaza, J. (1992). "Dual methods in entropy maximization. Applications to some problems in crystallography". SIAM Journal of Optimization, 2(2), 173-197. 
De Santis, R. (2012). "The euro area sovereign debt crisis: safe haven, credit rating agencies and the spread of the fever from Greece, Ireland and Portugal". ECB Working Paper No. 1419 .

Drehmann, M., \& Tarashev, N. (2011). "Systemic importance: Some simple indicators". BIS Quarterly Review, 12.

Engle, R., Jondeau, E., \& Rockinger, M. (2015). "Systemic risk in Europe". Review of Finance, 19(1), 145-190.

Gapen, M., Gray, D., Lim, C., \& Xiao, Y. (2008). "Measuring and analyzing sovereign risk with contingent claims". IMF Staff Papers, 55(1), 109-148.

Gerali, A., Neri, S., Sessa, L., \& Signoretti, F. (2010). "Credit and banking in a DSGE model of the euro area". Journal of Money, Credit and Banking, 42(s1), 107-141.

Gorea, D., \& Radev, D. (2014). "The euro area sovereign debt crisis: can contagion spread from the periphery to the core?". International Review of Economics and Finance, 30(1), $78-100$.

Hautsch, N., Schaumburg, J., \& Schienle, M. (2015). "Financial network systemic risk contributions". Review of Finance, 19(2), 685-738.

Huang, X., Zhou, H., \& Zhu, H. (2009). "A framework for assessing the systemic risk of major financial institutions". Journal of Banking and Finance, 33(11), 2036-2049.

Hull, J., \& White, A. (2000). "Valuing credit default swaps I: no counterparty default risk". Journal of Derivatives, 8(1), 29-40.

Idier, J., Lamé, G., \& Mésonnier, J. (2014). "How useful is the Marginal Expected Shortfall for the measurement of systemic exposure? A practical assessment". Journal of Banking and Finance, 47, 134-146.

Kim, D., Loretan, M., \& Remolona, E. (2010). "Contagion and risk premia in the amplification of crisis: evidence from Asian names in the global CDS market". Journal of Asian Economics, $21(3), 314-326$.

Lucas, A., Schwaab, B., \& Zhang, X. (2014). "Conditional euro area sovereign default risk". Journal of Business and Economic Statistics, 32(2), 271-284.

Pianeti, R., \& Giacometti, R. (2015). "Estimating the probability of multiple EU sovereign defaults using CDS and bond data". Quantitative Finance, 15(1), 61-78.

Puzanova, N., \& Düllmann, K. (2013). "Systemic risk contributions: a credit portfolio approach". Journal of Banking and Finance, 37(4), 1243-1257.

Radev, D. (2013). "Systemic risk and sovereign debt in the euro area". Gutenberg School of Management and Economics Discussion Paper No. 1207.

Segoviano, M. (2006). "Consistent information multivariate density optimization methodology". Financial Markets Group Discussion Paper No. 557.

Sturzenegger, F., \& Zettelmeyer, J. (2008). "Haircuts: estimating investor losses in sovereign debt restructurings, 1998-2005". Journal of International Money and Finance, 27(5), 780-805.

Tarashev, N., Borio, C., \& Tsatsaronis, K. (2009). "The systemic importance of financial institutions". BIS Quarterly Review. 


\section{Appendix A. The GCE method}

To dynamically update the posterior distribution, we need to solve for the Lagrange multipliers in equation (6) on a daily basis. We provide a solution to solve for consistent estimators of the Lagrange multipliers by using the GCE method. Under the cross-entropy postulate, we minimize the Csiszár measure of cross-entropy between the prior $q$ and the posterior $p$ as follows:

$$
\min _{p \in \mathbb{P}} D(p \rightarrow q)=\int_{\zeta} q(\mathbf{x}) \psi\left(\frac{p(\mathbf{x})}{q(\mathbf{x})}\right) d \mathbf{x}
$$

where $\mathbf{x}=\left[x_{1}, x_{2}, \cdots, x_{n}\right]^{T} \in \zeta \subset \mathbb{R}^{n}$ and $\mathbb{P}=\left\{p: \int p(\mathbf{x}) d \mathbf{x}=1, p(\mathbf{x}) \geq 0, \forall x \in \boldsymbol{\zeta}\right\}$. Additionally, $\psi$ is a function such that $\psi: \mathbb{R}^{+} \rightarrow \mathbb{R}$ is a continuous twice-differentiable function, $\psi(1)=0$, and $\psi^{\prime \prime}(x)>0 \forall x \in \mathbb{R}^{+}$. The minimization in equation (9) is subject to the generalized moment constraint set, $\Omega$ :

$$
\mathbb{E}_{p}\left[K_{i}(\mathbf{X})\right]=\int_{\zeta} p(\mathbf{x}) K_{i}(\mathbf{x}) d \mathbf{x}=\widehat{\kappa}_{i}, \text { for } i=1,2, \cdots, n
$$

where $K_{i}$ is a set of suitably chosen functions and $\widehat{\kappa}_{i}$ is some estimated quantity that describes the behaviour of the system.

The convexity assumption on $\psi$ allows us to invoke the theory of duality and, in particular, the strong duality theorem (e.g., Borwein \& Lewis, 1991; Decarreau, Hilhorst, Lemarechal, \& Navaza, 1992). We define the primal problem as

$$
\begin{gathered}
\min _{p} D(p \rightarrow q) \\
\text { subject to } \int p(\mathbf{x}) K_{i}(\mathbf{x}) d \mathbf{x}=\widehat{\kappa_{i}}, \quad i=1,2, \cdots, n \\
\int p(\mathbf{x}) d \mathbf{x}=1
\end{gathered}
$$

The corresponding Lagrangian is

$$
L\left(p: \boldsymbol{\lambda}, \lambda_{0}\right)=\int[q(\mathbf{x}) \psi\left(\frac{p(\mathbf{x})}{q(\mathbf{x})}\right)-p(\mathbf{x}) \underbrace{\sum_{i=0}^{n} \lambda_{i} K_{i}(\mathbf{x})}_{\text {Define } K_{0}(\cdot)=1}] d \mathbf{x}+\underbrace{\sum_{i=0}^{n} \lambda_{i} \widehat{\kappa_{i}}}_{\text {Define } \widehat{\kappa_{0}}=1}
$$

where $\boldsymbol{\lambda}=\left[\lambda_{1}, \lambda_{2}, \cdots, \lambda_{n}\right]^{T}$ and $\lambda_{0}$ denotes the set of positive Lagrange multipliers for $\Omega$.

Under the strong duality theorem, we obtain the following equivalence:

$$
\underbrace{\min _{p \in \mathbb{P}}\{D(p \rightarrow q)\}}_{\text {Primal problem }}=\underbrace{\max _{\boldsymbol{\lambda}, \lambda_{0}}\left\{\inf _{p \in \mathbb{P}} L\left(p: \boldsymbol{\lambda}, \lambda_{0}\right)\right\}}_{\text {Dual problem }}
$$


The equivalent dual problem is

$$
\begin{array}{r}
\max _{\boldsymbol{\lambda}, \lambda_{0}}\left\{\inf _{p \in \mathbb{P}} L\left(p: \boldsymbol{\lambda}, \lambda_{0}\right)\right\} \\
\text { subject to } \boldsymbol{\lambda} \geq 0
\end{array}
$$

Under the convexity assumption, the function $\psi^{\prime}(x)$ has a unique inverse over the positive reals. Thus,

$$
p(\mathbf{x})=q(\mathbf{x}) \psi^{\prime-1}\left(\sum_{i=0}^{n} \lambda_{i} K_{i}(\mathbf{x})\right)
$$

Substituting equation (14) into equation (11) and defining $\Psi^{\prime}(x)=\psi^{\prime-1}(x)$ yields the simplest form of the dual problem:

$$
\max _{\boldsymbol{\lambda}, \lambda_{0}} L^{*}\left(\boldsymbol{\lambda}, \lambda_{0}\right)=\sum_{i=0}^{n} \lambda_{i} \widehat{\kappa_{i}}-\mathbb{E}_{q}\left[\Psi\left(\sum_{i=0}^{n} \lambda_{i} K_{i}(\mathbf{X})\right)\right]
$$

The gradient of $L^{*}$ with respect to $\lambda_{j}$ is defined as

$$
\frac{\partial L^{*}}{\partial \lambda_{j}}=-\mathbb{E}_{q}\left[K_{j}(\mathbf{X}) \Psi^{\prime}\left(\sum_{i=0}^{n} \lambda_{i} K_{i}(\mathbf{X})\right)\right]+\widehat{\kappa_{j}} \text { for } j=0,1, \cdots, n
$$

Consistent estimators for $\boldsymbol{\lambda}, \lambda_{0}$, can be obtained by solving $\nabla_{\boldsymbol{\lambda}, \lambda_{0}} L^{*}=0$ :

$$
\begin{aligned}
\mathbb{E}_{q}\left[\Psi^{\prime}\left(\sum_{i=0}^{n} \lambda_{i} K_{i}(\mathbf{X})\right)\right] & =1 \\
\mathbb{E}_{q}\left[K_{1}(\mathbf{X}) \Psi^{\prime}\left(\sum_{i=0}^{n} \lambda_{i} K_{i}(\mathbf{X})\right)\right] & =\widehat{\kappa_{1}} \\
\vdots & \\
\mathbb{E}_{q}\left[K_{n}(\mathbf{X}) \Psi^{\prime}\left(\sum_{i=0}^{n} \lambda_{i} K_{i}(\mathbf{X})\right)\right] & =\widehat{\kappa_{n}}
\end{aligned}
$$

Generally, we can rarely calculate the expectations in the above system of equations analytically; thus, in practice, we numerically solve their stochastic counterparts:

$$
\frac{1}{n} \sum_{k=1}^{n}\left[K_{j}\left(\mathbf{x}_{k}\right) \Psi^{\prime}\left(\sum_{i=0}^{n} \lambda_{i} K_{i}\left(\mathbf{x}_{k}\right)\right)\right]=\widehat{\kappa_{j}}, \text { where }\left\{\mathbf{X}_{k}\right\}_{k=1}^{n} \sim q \text { and } j=0,1, \cdots, n
$$

The solution to this set of equations provides a set of consistent estimators for the Lagrange multipliers $\widehat{\boldsymbol{\lambda}}=\left[\widehat{\lambda_{1}}, \widehat{\lambda_{2}}, \cdots, \widehat{\lambda_{n}}\right]^{T}$ and $\widehat{\lambda_{0}}$.

To apply the GCE in the CIMDO framework, we first define $\psi(x)=x \ln (x)$ so that 
$\psi^{\prime}(x)=\ln (x)+1$ and $\psi^{\prime-1}(x)=\Psi^{\prime}(x)=\Psi(x)=\exp (x-1)$. Under this measure, the Csiszár cross-entropy distance is defined as

$$
D(p \rightarrow q)=\int_{\zeta} q(\mathbf{x}) \ln \left(\frac{p(\mathbf{x})}{q(\mathbf{x})}\right) d \mathbf{x}
$$

where $\mathbf{x} \in \zeta \subset \mathbb{R}^{n}, p(\mathbf{x}) \in \mathbb{R}^{n}$ is the posterior distribution, and $q(\mathbf{x}) \in \mathbb{R}^{n}$ is the prior distribution.

Our constraint set $\Omega$ is the set $\mathbb{E}_{p}\left[K_{i}(\mathbf{X})\right]=\widehat{\kappa_{i}}$ for $i=0,1, \cdots, n$, where $\widehat{\kappa_{0}}=1$ and $K_{0}(\cdot)=1$. We define $\left\{K_{i}(\mathbf{x})\right\}_{i=0}^{n}=\left\{\chi_{i}(\mathbf{x})\right\}_{i=0}^{n}$, where $\chi_{i}(\mathbf{x})$ is an indicator function that takes on the value of unity if $x_{i}$ satisfies some condition and zero otherwise. Therefore, our constraint set becomes $\mathbb{E}_{p}\left[\chi_{i}(\mathbf{X})\right]=\widehat{\kappa}_{i}$ for $i=0,1, \cdots, n$.

The primal problem is defined as

$$
\begin{gathered}
\min _{p} D(p \rightarrow q)=\int_{\zeta} q(\mathbf{x}) \ln \left(\frac{p(\mathbf{x})}{q(\mathbf{x})}\right) d \mathbf{x} \\
\text { subject to } \mathbb{E}_{p}\left[\chi_{i}(\mathbf{X})\right]=\widehat{\kappa_{i}} \text { for } i=0,1, \cdots, n
\end{gathered}
$$

The solution to the primal problem using equation (14) is given by

$$
p(\mathbf{x})=q(\mathbf{x}) \exp \left[\sum_{i=0}^{n} \lambda_{i} \chi_{i}(\mathbf{x})-1\right]
$$

To see the equivalence between equation (21) and the CIMDO posterior distribution given by equation (6), we define the Lagrange multipliers as inherently negative and denote $\lambda_{0}$ as $\mu$, yielding the following equivalent expression:

$$
\widehat{p(\mathbf{x})}=q(\mathbf{x}) \exp \left\{-\left[1+\widehat{\mu}+\sum_{i=1}^{n} \widehat{\lambda_{i}} \chi_{i}(\mathbf{x})\right]\right\}
$$

We use equation (15) to solve for the Lagrange multipliers

$$
\max _{\boldsymbol{\lambda}, \lambda_{0}}\left\{\sum_{i=0}^{n} \lambda_{i} P o D_{I_{i}}-\mathbb{E}_{q}\left[\exp \left(\sum_{i=0}^{n} \lambda_{i} \chi_{i}(\mathbf{X})-1\right)\right]\right\}
$$

where $P o D_{I_{0}}=1$ and $\chi_{0}(\cdot)=1$.

To maximize equation (23), we solve the following system of equations:

$$
\begin{aligned}
\mathbb{E}_{q}\left[\exp \left(\sum_{i=0}^{n} \lambda_{i} \chi_{i}(\mathbf{X})-1\right)\right] & =1 \\
\mathbb{E}_{q}\left[\chi_{j}(\mathbf{X}) \exp \left(\sum_{i=0}^{n} \lambda_{i} \chi_{i}(\mathbf{X})-1\right)\right] & =\operatorname{PoD}_{I_{j}}
\end{aligned}
$$

for $j=1,2, \cdots, n$. We numerically solve the above system of equations using equation (20), thereby obtaining a set of consistent estimators for the Lagrange multipliers $\widehat{\mu}, \widehat{\lambda_{1}}, \cdots, \widehat{\lambda_{n}}$. 


\section{Appendix B. Description of major events}

The following briefly describes the major events on specific dates presented in Figure 7.

(1) 14 March 2008: JP Morgan and the Federal Reserve bail out Bear Stearns.

(2) 7 July 2008: Freddie Mac, Fannie Mae plunge on capital concerns.

(3) 15 September 2008: Lehman Brothers file the largest bankruptcy after suitors balk.

(4) 15 November 2008: G20 summit seeks to boost growth and prevent crisis.

(5) 10 March 2009: US stock market hits bottom as measured by the Dow Jones Industrial Average.

(6) 2 April 2009: G20 to set up the Financial Stability Board.

(7) 2 May 2010: The EA countries and the IMF agree on a $€ 110$ billion loan package to Greece.

(8) 23 July 2010: The Committee of European Banking Supervisors publishes the results of banking stress tests.

(9) 12 January 2011: News regarding the expansion of the European Financial Stability Facility dissipated into the financial markets.

(10) 19 February 2011: G20 to focus on imbalances.

(11) 15 July 2011: The European Banking Authority publishes the results of the 2011 round of banking stress tests.

(12) 14 October 2011: G20 pledges to preserve financial stability.

(13) 30 November 2011: The Federal Reserve coordinates global effort with other central banks to lower prices on dollar liquidity swaps.

(14) 21 December 2011: The ECB implements the first three-year long-term refinancing operation, offering loans at low interest rates.

(15) 21 February 2012: Eurogroup agrees on a second financial aid package for Greece.

(16) 20 July 2012: Eurogroup grants financial assistance to Spain's banking sector.

(17) 4 February 2013: Statement by the European Commission and the ECB on the second review of a financial assistance programme for Spain. 


\section{Tables}

Table 1. List of sovereigns and banks.

\begin{tabular}{lcccc}
\hline Sovereigns & \multicolumn{3}{c}{ Banks } \\
\cline { 2 - 5 } & Bank & Country & Bank & Country \\
\hline Austria (AUT) & Erste Group Bank AG & Austria & Intesa Sanpaolo SpA & Italy \\
Belgium (BEL) & Raiffeisen Bank & Austria & Mediobanca SpA & Italy \\
Denmark (DEN) & Dexia SA & Belgium & UniCredit SpA & Italy \\
France (FRA) & KBC Groep NV & Belgium & Banco Comercial Portugues SA & Portugal \\
Germany (GER) & Danske Bank A/S & Denmark & Espirito Santo Financial Group & Portugal \\
Greece (GRE) & BNP Paribas & France & Banco Bilbao Vizcaya & Spain \\
Ireland (IRE) & Crédit Agricole SA & France & Banco de Sabadell SA & Spain \\
Italy (ITA) & Natixis & France & Banco Santander SA & Spain \\
Norway (NOR) & Société Générale & France & Nordea Bank & Sweden \\
Portugal (POR) & Commerzbank AG & Germany & Skandinaviska Enskilda Banken & Sweden \\
Spain (SPA) & Deutsche Bank AG & Germany & Svenska Handelsbanken AB & Sweden \\
Sweden (SWE) & IKB Bank & Germany & Swedbank AB & Sweden \\
Netherlands (NL) & Alpha Bank & Greece & Credit Suisse Group & Switzerland \\
United Kingdom (UK) & Allied Irish Banks PLC & Ireland & UBS SG & Switzerland \\
& Irish Life and Permanent & Ireland & ING Groep NV & Netherlands \\
& Bank of Ireland & Ireland & SNS Bank Netherlands & Netherlands \\
& Banca Italease & Italy & Barclays PLC & United Kingdom \\
& Banca Monte dei Paschi di Siena & Italy & HBOS PLC & United Kingdom \\
& Banca Popolare di Milano & Italy & Lloyds Banking Group & United Kingdom \\
& Banco Popolare SC & Italy & Standard Chartered & United Kingdom \\
\hline
\end{tabular}

Notes: This table presents the 14 sovereigns and 40 banks used in our analyses. Next to each sovereign is its abbreviated name in parentheses. The home country for each bank is also reported. We do not include Switzerland as a sovereign because its sovereign CDS contract is not informative enough for the majority of our sample period. For the same reason, we do not include any banks from Norway. 
Table 2. Sovereign correlation matrix.

\begin{tabular}{|c|c|c|c|c|c|c|c|c|c|c|c|c|c|c|}
\hline & AUT & BEL & DEN & FRA & GER & GRE & IRE & ITA & NOR & POR & SPA & SWE & NL & UK \\
\hline AUT & 1.00 & 0.68 & 0.68 & 0.68 & 0.66 & 0.09 & 0.48 & 0.56 & 0.46 & 0.38 & 0.55 & 0.64 & 0.72 & 0.65 \\
\hline BEL & & 1.00 & 0.60 & 0.78 & 0.67 & 0.16 & 0.58 & 0.72 & 0.39 & 0.53 & 0.73 & 0.45 & 0.66 & 0.56 \\
\hline DEN & & & 1.00 & 0.61 & 0.62 & 0.12 & 0.45 & 0.54 & 0.46 & 0.37 & 0.51 & 0.66 & 0.66 & 0.58 \\
\hline FRA & & & & 1.00 & 0.72 & 0.16 & 0.51 & 0.70 & 0.42 & 0.48 & 0.69 & 0.46 & 0.65 & 0.53 \\
\hline GER & & & & & 1.00 & 0.11 & 0.47 & 0.58 & 0.45 & 0.44 & 0.59 & 0.54 & 0.67 & 0.59 \\
\hline GRE & & & & & & 1.00 & 0.12 & 0.13 & 0.08 & 0.12 & 0.16 & 0.07 & 0.11 & 0.06 \\
\hline IRE & & & & & & & 1.00 & 0.56 & 0.33 & 0.65 & 0.61 & 0.37 & 0.46 & 0.46 \\
\hline ITA & & & & & & & & 1.00 & 0.35 & 0.57 & 0.85 & 0.38 & 0.56 & 0.48 \\
\hline NOR & & & & & & & & & 1.00 & 0.25 & 0.35 & 0.47 & 0.47 & 0.42 \\
\hline POR & & & & & & & & & & 1.00 & 0.61 & 0.25 & 0.35 & 0.36 \\
\hline SPA & & & & & & & & & & & 1.00 & 0.38 & 0.55 & 0.49 \\
\hline SWE & & & & & & & & & & & & 1.00 & 0.62 & 0.57 \\
\hline NL & & & & & & & & & & & & & 1.00 & 0.65 \\
\hline UK & & & & & & & & & & & & & & 1.00 \\
\hline
\end{tabular}

Notes: This table presents the sample average correlation matrix between the 14 sovereigns. The correlation coefficients between any two sovereigns are based on the average of the correlation coefficients used in the construction of the dynamic sovereign variance-covariance matrices. The abbreviations of the sovereigns are listed in Table 1. All CDS contracts are denominated in USD and the sample period is from 1 January 2008 to 31 December 2013. 
Table 3. Conditional joint probability of default of the banking system given the default of individual banks on specific dates.

\begin{tabular}{|c|c|c|c|c|c|c|c|c|}
\hline \multirow[t]{2}{*}{ Bank } & \multirow[t]{2}{*}{ Country } & \multicolumn{5}{|c|}{ Conditional joint probability of default } & \multirow{2}{*}{$\begin{array}{l}\text { Total } \\
\text { assets }\end{array}$} & \multirow{2}{*}{$\begin{array}{c}\text { Total } \\
\text { liabilities }\end{array}$} \\
\hline & & $\begin{array}{l}15 \text { Sept } \\
2008\end{array}$ & $\begin{array}{l}10 \text { Mar } \\
2009\end{array}$ & $\begin{array}{c}2 \text { May } \\
2010\end{array}$ & $\begin{array}{l}25 \text { Nov } \\
2011\end{array}$ & $\begin{array}{l}19 \text { Dec } \\
2013\end{array}$ & & \\
\hline Erste Group Bank AG & AUT & 0.084 & 0.133 & 0.094 & 0.201 & 0.091 & 209.30 & 194.12 \\
\hline Raiffeisen Bank & AUT & 0.094 & 0.121 & 0.080 & 0.256 & 0.097 & 146.63 & 135.69 \\
\hline Dexia SA & BEL & 0.052 & 0.111 & 0.059 & 0.154 & 0.060 & 412.05 & 412.37 \\
\hline KBC Groep NV & BEL & 0.145 & 0.140 & 0.123 & 0.256 & 0.134 & 282.94 & 266.17 \\
\hline Danske Bank A/S & DEN & 0.071 & 0.118 & 0.071 & 0.191 & 0.075 & 342.26 & 329.68 \\
\hline BNP Paribas & FRA & 0.230 & 0.293 & 0.209 & 0.333 & 0.208 & 1955.94 & 1870.31 \\
\hline Crédit Agricole SA & FRA & 0.156 & 0.286 & 0.151 & 0.330 & 0.162 & 1718.51 & 1669.22 \\
\hline Natixis & FRA & 0.108 & 0.119 & 0.146 & 0.404 & 0.164 & 504.50 & 487.11 \\
\hline Société Générale & FRA & 0.168 & 0.285 & 0.167 & 0.278 & 0.166 & 1176.79 & 1125.68 \\
\hline Commerzbank AG & GER & 0.182 & 0.335 & 0.180 & 0.277 & 0.153 & 657.61 & 630.23 \\
\hline Deutsche Bank AG & GER & 0.182 & 0.262 & 0.146 & 0.322 & 0.204 & 2155.37 & 2100.71 \\
\hline IKB Bank & GER & 0.038 & 0.052 & 0.055 & 0.202 & 0.051 & 31.25 & 30.27 \\
\hline Alpha Bank & GRE & 0.034 & 0.060 & 0.031 & 0.096 & 0.035 & 57.68 & 56.25 \\
\hline $\begin{array}{l}\text { Allied Irish Banks } \\
\text { PLC }\end{array}$ & IRE & 0.040 & 0.062 & 0.037 & 0.124 & 0.019 & 132.96 & 118.50 \\
\hline $\begin{array}{l}\text { Irish Life and } \\
\text { Permanent }\end{array}$ & IRE & 0.038 & 0.071 & 0.039 & 0.097 & 0.090 & 71.85 & 68.34 \\
\hline Bank of Ireland & IRE & 0.035 & 0.061 & 0.040 & 0.109 & 0.092 & 153.50 & 143.25 \\
\hline Banca Italease & ITA & 0.030 & 0.043 & 0.081 & 0.336 & 0.105 & 10.53 & 8.89 \\
\hline $\begin{array}{l}\text { Banca Monte dei } \\
\text { Paschi di Siena }\end{array}$ & ITA & 0.117 & 0.261 & 0.115 & 0.205 & 0.068 & 234.03 & 223.05 \\
\hline $\begin{array}{l}\text { Banca Popolare di } \\
\text { Milano }\end{array}$ & ITA & 0.166 & 0.232 & 0.132 & 0.224 & 0.079 & 51.22 & 47.16 \\
\hline Banco Popolare SC & ITA & 0.110 & 0.119 & 0.090 & 0.157 & 0.084 & 130.86 & 121.44 \\
\hline Intesa Sanpaolo SpA & ITA & 0.158 & 0.242 & 0.131 & 0.230 & 0.162 & 626.90 & 579.14 \\
\hline Mediobanca SpA & ITA & 0.152 & 0.242 & 0.129 & 0.259 & 0.152 & 74.80 & 67.77 \\
\hline UniCredit SpA & ITA & 0.133 & 0.162 & 0.116 & 0.336 & 0.164 & 914.11 & 859.31 \\
\hline $\begin{array}{c}\text { Banco Comercial } \\
\text { Portugues SA }\end{array}$ & POR & 0.097 & 0.147 & 0.078 & 0.148 & 0.075 & 91.92 & 87.54 \\
\hline $\begin{array}{c}\text { Espirito Santo } \\
\text { Financial Group }\end{array}$ & POR & 0.076 & 0.126 & 0.075 & 0.198 & 0.092 & 79.53 & 73.54 \\
\hline Banco Bilbao Vizcaya & SPA & 0.185 & 0.251 & 0.154 & 0.321 & 0.164 & 597.69 & 552.44 \\
\hline Banco de Sabadell SA & SPA & 0.067 & 0.120 & 0.085 & 0.195 & 0.103 & 100.44 & 93.60 \\
\hline Banco Santander SA & SPA & 0.178 & 0.249 & 0.169 & 0.325 & 0.163 & 1251.53 & 1162.77 \\
\hline Nordea Bank & SWE & 0.108 & 0.193 & 0.097 & 0.243 & 0.110 & 716.20 & 688.06 \\
\hline Skandinaviska & SWE & 0.077 & 0.112 & 0.073 & 0.192 & 0.078 & 264.76 & 252.09 \\
\hline $\begin{array}{c}\text { Enskilda Banken } \\
\text { Svenska } \\
\text { Handelsbanken AB }\end{array}$ & SWE & 0.118 & 0.196 & 0.112 & 0.285 & 0.112 & 275.42 & 263.22 \\
\hline Swedbank AB & SWE & 0.058 & 0.090 & 0.070 & 0.195 & 0.071 & 208.39 & 196.62 \\
\hline Credit Suisse Group & SWI & 0.210 & 0.265 & 0.209 & 0.405 & 0.186 & 861.83 & 819.14 \\
\hline UBS SG & SWI & 0.151 & 0.194 & 0.159 & 0.351 & 0.196 & 1163.96 & 1120.48 \\
\hline ING Groep NV & NL & 0.083 & 0.199 & 0.114 & 0.259 & 0.174 & 1270.56 & 1223.33 \\
\hline SNS Bank Netherlands & NL & 0.128 & 0.072 & 0.056 & 0.165 & 0.039 & 128.21 & 123.64 \\
\hline Barclays PLC & UK & 0.119 & 0.185 & 0.167 & 0.317 & 0.142 & 1560.52 & 1495.32 \\
\hline HBOS PLC & UK & 0.065 & 0.209 & 0.115 & 0.317 & 0.217 & 568.00 & 540.36 \\
\hline Lloyds Banking Group & UK & 0.166 & 0.207 & 0.117 & 0.228 & 0.156 & 966.05 & 919.46 \\
\hline Standard Chartered & UK & 0.201 & 0.126 & 0.219 & 0.417 & 0.116 & 385.26 & 358.62 \\
\hline
\end{tabular}

Notes: This table presents the conditional joint probability of default of the banking system given the default of each bank in the first column. We also report the home country of each bank in the second column. The third to seventh columns give the values of the conditional joint probability of default on five specific dates. The eighth and ninth columns give the total assets and total liabilities, respectively, of each bank in 2011, in billions of euros. 
Table 4. Decomposition of systemic risk.

\begin{tabular}{|c|c|c|c|c|c|c|c|}
\hline & $(1)$ & $(2)$ & $(3)$ & $(4)$ & $(5)$ & (6) & (7) \\
\hline & & & & & & \multicolumn{2}{|c|}{ Sovereign subsample } \\
\hline & & & & & & Peripheral & $\begin{array}{c}\text { Non- } \\
\text { peripheral }\end{array}$ \\
\hline Constant & $\begin{array}{l}0.043^{* *} \\
(2.31)\end{array}$ & $\begin{array}{l}0.042^{* *} \\
(2.30)\end{array}$ & $\begin{array}{l}0.040^{* *} \\
(2.15)\end{array}$ & $\begin{array}{l}0.043^{* *} \\
(2.30)\end{array}$ & $\begin{array}{l}0.038^{* *} \\
(2.14)\end{array}$ & $\begin{array}{c}0.033^{*} \\
(1.86)\end{array}$ & $\begin{array}{c}0.036^{*} \\
(1.96)\end{array}$ \\
\hline$L R P$ & $\begin{array}{l}-0.016^{*} \\
(-1.67)\end{array}$ & & & & $\begin{array}{l}-0.031^{* * *} \\
(-3.17)\end{array}$ & $\begin{array}{l}-0.036^{* *} \\
(-2.25)\end{array}$ & $\begin{array}{l}-0.028^{* *} \\
(-2.28)\end{array}$ \\
\hline$D R P$ & & $\begin{array}{l}0.220^{* * *} \\
(6.15)\end{array}$ & & & $\begin{array}{l}0.274^{* * *} \\
(7.42)\end{array}$ & $\begin{array}{l}0.226^{* * *} \\
(3.76)\end{array}$ & $\begin{array}{l}0.298^{* * *} \\
(6.36)\end{array}$ \\
\hline$S R P$ & & & $\begin{array}{l}0.085^{* *} \\
(2.15)\end{array}$ & & $\begin{array}{l}0.195^{* * *} \\
(4.75)\end{array}$ & $\begin{array}{l}0.141^{* *} \\
(2.10)\end{array}$ & $\begin{array}{l}0.220^{* * *} \\
(4.21)\end{array}$ \\
\hline$D T D$ & & & & $\begin{array}{l}-0.002^{*} \\
(-1.68)\end{array}$ & $\begin{array}{l}-0.003^{*} \\
(-1.77)\end{array}$ & $\begin{array}{l}-0.004^{* *} \\
(-2.50)\end{array}$ & $\begin{array}{r}0.002 \\
(0.63)\end{array}$ \\
\hline Itraxx & $\begin{array}{l}0.211^{* * *} \\
(5.08)\end{array}$ & $\begin{array}{l}0.157^{* * *} \\
(3.77)\end{array}$ & $\begin{array}{l}0.214^{* * *} \\
(5.19)\end{array}$ & $\begin{array}{l}0.219^{* * *} \\
(5.32)\end{array}$ & $\begin{array}{l}0.113^{* * *} \\
(2.70)\end{array}$ & $\begin{array}{l}0.140^{* *} \\
(2.05)\end{array}$ & $\begin{array}{c}0.099^{*} \\
(1.87)\end{array}$ \\
\hline Market & $\begin{array}{l}-1.362^{* * *} \\
(-12.90)\end{array}$ & $\begin{array}{l}-1.107^{* * *} \\
(-10.12)\end{array}$ & $\begin{array}{l}-1.268^{* * *} \\
(-11.60)\end{array}$ & $\begin{array}{l}-1.338^{* * *} \\
(-12.8)\end{array}$ & $\begin{array}{l}-0.938^{* * *} \\
(-8.09)\end{array}$ & $\begin{array}{l}-0.962^{* * *} \\
(-5.09)\end{array}$ & $\begin{array}{l}-0.934^{* * *} \\
(-6.36)\end{array}$ \\
\hline Vstoxx & $\begin{array}{l}0.191^{* * *} \\
(5.51)\end{array}$ & $\begin{array}{l}0.173^{* * *} \\
(5.21)\end{array}$ & $\begin{array}{l}0.161^{* * *} \\
(4.64)\end{array}$ & $\begin{array}{l}0.179^{* * *} \\
(5.28)\end{array}$ & $\begin{array}{l}0.156^{* * *} \\
(4.57)\end{array}$ & $\begin{array}{l}0.185^{* * *} \\
(3.32)\end{array}$ & $\begin{array}{l}0.144^{* * *} \\
(3.31)\end{array}$ \\
\hline Sovereign fixed effects & Yes & Yes & Yes & Yes & Yes & Yes & Yes \\
\hline Observations & 924 & 924 & 924 & 924 & 924 & 330 & 594 \\
\hline Adjusted $R^{2}$ & 0.531 & 0.549 & 0.532 & 0.531 & 0.562 & 0.567 & 0.559 \\
\hline Number of banks & 40 & 40 & 40 & 40 & 40 & 16 & 24 \\
\hline Number of sovereigns & 14 & 14 & 14 & 14 & 14 & 5 & 9 \\
\hline
\end{tabular}

Notes: This table presents the decomposition of systemic risk according to the panel regression specification in equation (8). The dependent variable for all seven columns is the conditional joint probability of default of the sovereign system given the joint default of all banks in a particular sovereign. The variable $L R P$ is the liquidity risk premium calculated by using the daily three-month euro LIBOR-OIS (or EURIBOR-EONIA) spread; $D R P$ is the default risk premium calculated by using the daily difference between the yields of 10-year euro zone industrials rated $\mathrm{BBB}$ and those rated $\mathrm{AA}+/ \mathrm{AA} ; S R P$ is the sovereign risk premium calculated by using the daily difference between Germany's 10-year generic yield with the average of the Spanish and Italian 10-year generic yields weighted by their quarterly real GDPs; DTD is the average DTD of all banks within a particular sovereign; Itraxx is the European iTraxx index; Market is the EU stock market index; and Vstoxx is the Vstoxx volatility index. Columns (1) to (5) use the full sample of 40 banks from 14 sovereigns. Columns (6) and (7) use banks from peripheral and non-peripheral sovereigns, respectively. The sample period consists of monthly observations from 1 January 2008 to 28 June 2013. All columns use sovereign fixed effects; $t$-statistics are shown in parentheses; and the superscripts $*, * *$, and $* * *$ indicate statistical significance at the $10 \%, 5 \%$, and $1 \%$ levels, respectively. 
Table 5. Alternative specifications for the decomposition of systemic risk.

\begin{tabular}{|c|c|c|c|c|c|c|c|c|}
\hline & (1) & (2) & (3) & (4) & (5) & (6) & (7) & (8) \\
\hline & \multicolumn{3}{|c|}{ GSIB banks removed } & \multicolumn{3}{|c|}{ SRISK } & \multicolumn{2}{|c|}{ Crisis dummies } \\
\hline & Full & Peripheral & $\begin{array}{c}\text { Non- } \\
\text { peripheral }\end{array}$ & Full & Peripheral & $\begin{array}{c}\text { Non- } \\
\text { peripheral }\end{array}$ & Peripheral & $\begin{array}{c}\text { Non- } \\
\text { peripheral }\end{array}$ \\
\hline Constant & $\begin{array}{c}0.104 \\
(1.53)\end{array}$ & $\begin{array}{l}0.041^{* *} \\
(2.27)\end{array}$ & $\begin{array}{r}0.098 \\
(1.50)\end{array}$ & $\begin{array}{l}0.036^{*} \\
(1.86)\end{array}$ & $\begin{array}{l}0.033^{*} \\
(1.86)\end{array}$ & $\begin{array}{l}0.035^{*} \\
(1.80)\end{array}$ & $\begin{array}{c}0.014 \\
(1.07)\end{array}$ & $\begin{array}{c}0.019 \\
(1.36)\end{array}$ \\
\hline GFC dummy & & & & & & & $\begin{array}{l}0.051^{* *} \\
(2.53)\end{array}$ & $\begin{array}{l}0.059^{* * *} \\
(4.08)\end{array}$ \\
\hline$S D C$ dummy & & & & & & & $\begin{array}{l}-0.001 \\
(-0.07)\end{array}$ & $\begin{array}{l}-0.008 \\
(-1.05)\end{array}$ \\
\hline$L R P$ & $\begin{array}{l}-0.033^{* * *} \\
(-5.29)\end{array}$ & $\begin{array}{l}-0.035^{* * *} \\
(-3.83)\end{array}$ & $\begin{array}{l}-0.031^{* * *} \\
(-3.57)\end{array}$ & $\begin{array}{l}-0.030^{* * *} \\
(-5.48)\end{array}$ & $\begin{array}{l}-0.034^{* * *} \\
(-3.54)\end{array}$ & $\begin{array}{l}-0.028^{* * *} \\
(-4.05)\end{array}$ & $\begin{array}{l}-0.017^{* *} \\
(-2.08)\end{array}$ & $\begin{array}{l}-0.013^{* *} \\
(-2.09)\end{array}$ \\
\hline$L R P \times G F C$ dummy & & & & & & & $\begin{array}{l}-0.101^{* * *} \\
(-3.07)\end{array}$ & $\begin{array}{l}-0.068^{* *} \\
(-2.28)\end{array}$ \\
\hline$L R P \times S D C$ dummy & & & & & & & $\begin{array}{l}-0.036^{*} \\
(-1.82)\end{array}$ & $\begin{array}{l}-0.042^{* * *} \\
(-2.83)\end{array}$ \\
\hline$D R P$ & $\begin{array}{l}0.264^{* * *} \\
(3.25)\end{array}$ & $\begin{array}{l}0.219^{*} \\
(1.78)\end{array}$ & $\begin{array}{l}0.292^{* * *} \\
(2.70)\end{array}$ & $\begin{array}{l}0.274^{* * *} \\
(3.51)\end{array}$ & $\begin{array}{l}0.229^{*} \\
(1.84)\end{array}$ & $\begin{array}{l}0.299^{* * *} \\
(2.98)\end{array}$ & $\begin{array}{l}-0.274^{* * *} \\
(-3.26)\end{array}$ & $\begin{array}{l}-0.236^{* * *} \\
(-3.65)\end{array}$ \\
\hline$D R P \times G F C$ dummy & & & & & & & $\begin{array}{l}1.144^{* * *} \\
(11.03)\end{array}$ & $\begin{array}{l}1.209^{* *} \\
(13.63)\end{array}$ \\
\hline$D R P \times S D C$ dummy & & & & & & & $\begin{array}{c}0.068 \\
(0.83)\end{array}$ & $\begin{array}{c}0.075 \\
(1.19)\end{array}$ \\
\hline$S R P$ & $\begin{array}{l}0.180^{* * *} \\
(4.35)\end{array}$ & $\begin{array}{l}0.142^{* *} \\
(2.28)\end{array}$ & $\begin{array}{l}0.204^{* * *} \\
(3.65)\end{array}$ & $\begin{array}{l}0.194^{* * *} \\
(5.24)\end{array}$ & $\begin{array}{l}0.147^{* *} \\
(2.46)\end{array}$ & $\begin{array}{l}0.223^{* * *} \\
(4.75)\end{array}$ & $\begin{array}{l}0.223^{* * *} \\
(3.64)\end{array}$ & $\begin{array}{l}0.302^{* * *} \\
(6.49)\end{array}$ \\
\hline$S R P \times G F C$ dummy & & & & & & & $\begin{array}{l}-0.175^{* *} \\
(-2.39)\end{array}$ & $\begin{array}{l}-0.159^{* * *} \\
(-2.98)\end{array}$ \\
\hline$S R P \times S D C$ dummy & & & & & & & $\begin{array}{l}0.608^{* * *} \\
(3.75)\end{array}$ & $\begin{array}{l}0.586^{* * *} \\
(4.93)\end{array}$ \\
\hline$D T D$ & $\begin{array}{l}-0.001 \\
(-0.91)\end{array}$ & $\begin{array}{l}-0.006^{* *} \\
(-1.97)\end{array}$ & $\begin{array}{l}-0.001 \\
(-0.71)\end{array}$ & & & & $\begin{array}{l}-0.008^{* *} \\
(-2.01)\end{array}$ & $\begin{array}{c}0.005 \\
(0.61)\end{array}$ \\
\hline$D T D \times G F C$ dummy & & & & & & & $\begin{array}{r}0.006 \\
(1.41)\end{array}$ & $\begin{array}{l}-0.006 \\
(-0.73)\end{array}$ \\
\hline$D T D \times S D C$ dummy & & & & & & & $\begin{array}{r}0.006 \\
(1.58)\end{array}$ & $\begin{array}{l}-0.007 \\
(-0.89)\end{array}$ \\
\hline SRISK & & & & $\begin{array}{r}0.001 \\
(0.00)\end{array}$ & $\begin{array}{l}0.207^{* *} \\
(2.09)\end{array}$ & $\begin{array}{l}-0.070 \\
(-0.60)\end{array}$ & & \\
\hline Itraxx & $\begin{array}{l}0.150^{* *} \\
(2.53)\end{array}$ & $\begin{array}{c}0.150 \\
(1.64)\end{array}$ & $\begin{array}{l}0.149^{*} \\
(1.92)\end{array}$ & $\begin{array}{l}0.114^{* *} \\
(2.01)\end{array}$ & $\begin{array}{c}0.128 \\
(1.49)\end{array}$ & $\begin{array}{c}0.104 \\
(1.41)\end{array}$ & $\begin{array}{l}0.227^{* * *} \\
(5.38)\end{array}$ & $\begin{array}{l}0.207^{* * *} \\
(6.51)\end{array}$ \\
\hline Market & $\begin{array}{l}-0.995^{\text {*** }} \\
(-8.12)\end{array}$ & $\begin{array}{l}-0.972^{* * *} \\
(-5.15)\end{array}$ & $\begin{array}{l}-1.014^{* * *} \\
(-6.27)\end{array}$ & $\begin{array}{l}-0.938^{* * *} \\
(-7.20)\end{array}$ & $\begin{array}{l}-1.054^{* * *} \\
(-5.02)\end{array}$ & $\begin{array}{l}-0.890^{* * *} \\
(-5.33)\end{array}$ & $\begin{array}{l}-1.163^{* * *} \\
(-7.19)\end{array}$ & $\begin{array}{l}-1.179^{* * *} \\
(-9.51)\end{array}$ \\
\hline Vstoxx & $\begin{array}{l}0.163^{\text {*** }} \\
(5.14)\end{array}$ & $\begin{array}{l}0.185^{\text {*** }} \\
(3.87)\end{array}$ & $\begin{array}{l}0.148^{* * *} \\
(3.49)\end{array}$ & $\begin{array}{l}0.156^{* * *} \\
(5.20)\end{array}$ & $\begin{array}{l}0.172^{* * *} \\
(3.47)\end{array}$ & $\begin{array}{l}0.146^{* * *} \\
(3.89)\end{array}$ & $\begin{array}{l}0.103^{*} \\
(1.90)\end{array}$ & $\begin{array}{l}0.172^{* * *} \\
(4.01)\end{array}$ \\
\hline Sovereign fixed effects & Yes & Yes & Yes & Yes & Yes & Yes & Yes & Yes \\
\hline Observations & 800 & 330 & 470 & 924 & 330 & 594 & 330 & 594 \\
\hline Adjusted $R^{2}$ & 0.578 & 0.564 & 0.584 & 0.560 & 0.559 & 0.558 & 0.776 & 0.780 \\
\hline Number of banks & 24 & 13 & 11 & 36 & 14 & 22 & 16 & 24 \\
\hline Number of sovereigns & 13 & 5 & 8 & 14 & 5 & 9 & 5 & 9 \\
\hline
\end{tabular}

Notes: This table presents alternative specifications for the decomposition of systemic risk. The dependent variable for all eight columns is the conditional joint probability of default of the sovereign system given the joint default of all banks in a particular sovereign. The additional explanatory variables are defined as follows. The variable GFC dummy is a dummy variable equal to one if the period is from January 2008 to April 2009 and zero otherwise, $S D C$ dummy is a dummy variable equal to one if the period is from January 2011 to July 2012 and zero otherwise, and SRISK is the average SRISK value of all banks within a particular sovereign. Columns (1) and (4) use the full sample of banks. Columns (2), (5), and (7) use banks from peripheral sovereigns while columns (3), (6), and (8) use banks from non-peripheral sovereigns. The sample period consists of monthly observations from 1 January 2008 to 28 June 2013. All columns use sovereign fixed effects; $t$-statistics are shown in parentheses; and the superscripts *, $* *$, and ${ }^{* * *}$ indicate statistical significance at the $10 \%, 5 \%$, and $1 \%$ levels, respectively. 


\section{Figures}

(a) Core sovereigns

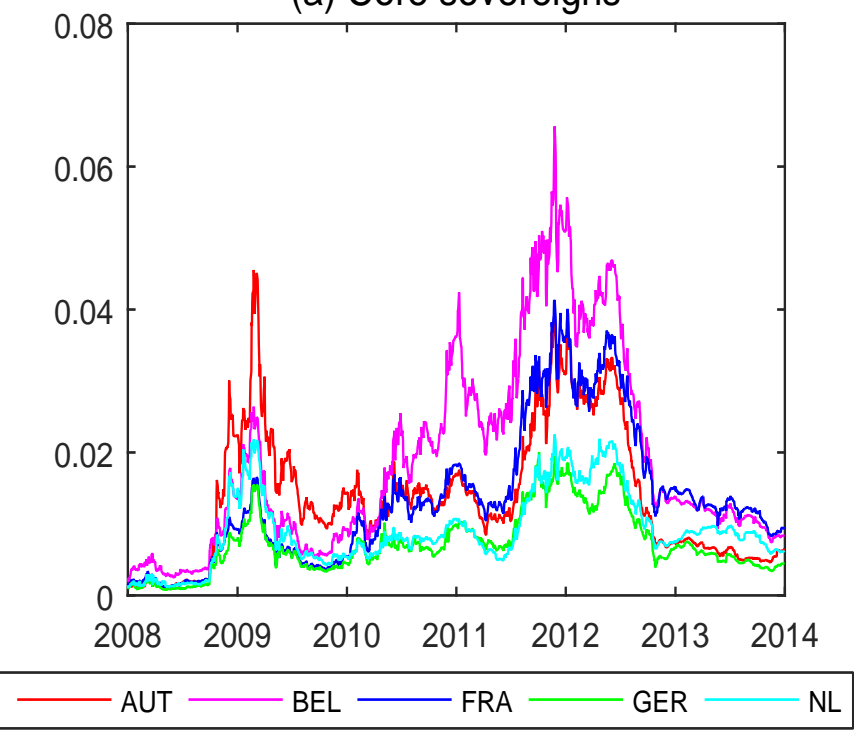

(c) Non-EA sovereigns

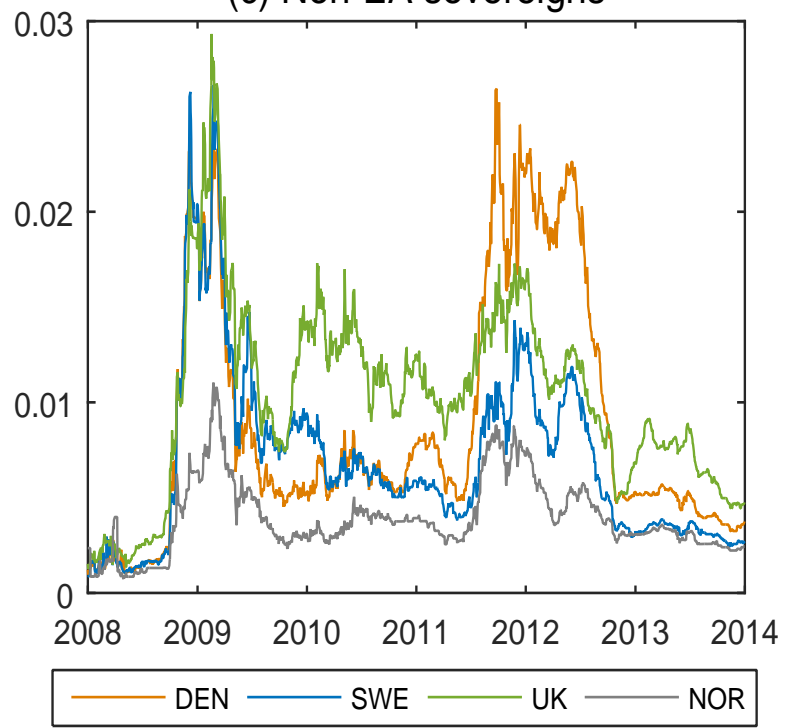

(b) Peripheral sovereigns

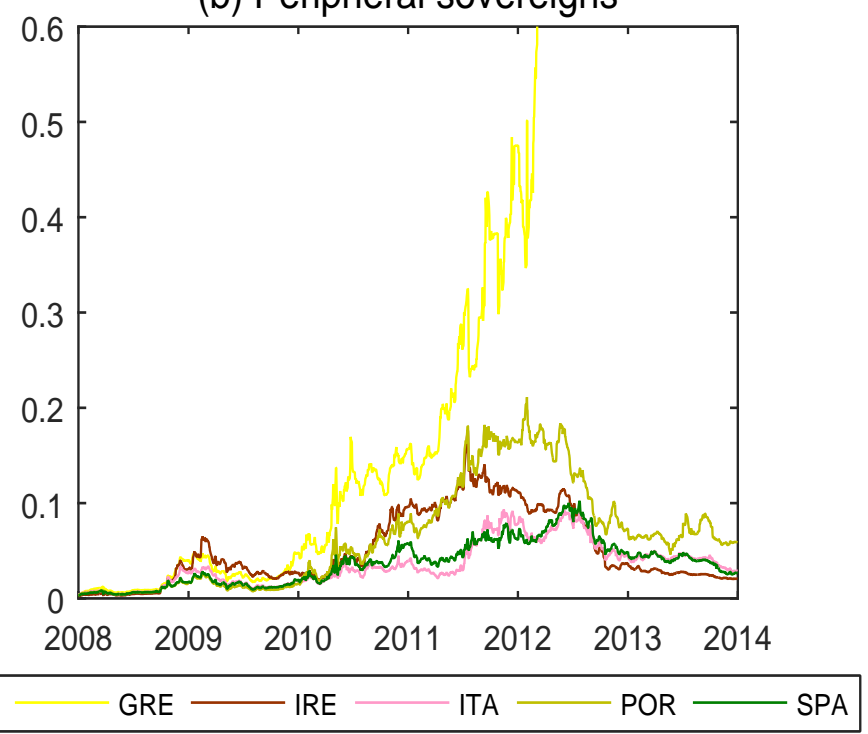

(d) JPoD

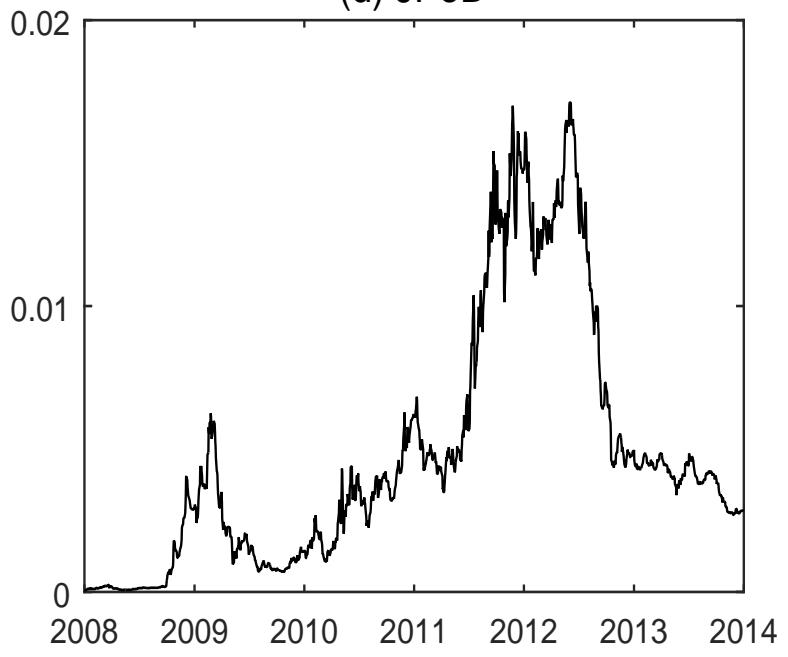

Figure 1. Sovereign probabilities of default and joint probability of default of the sovereign system. Note: Panels (a), (b), and (c) present the five-year annualized bootstrapped probabilities of default for each sovereign in the core, peripheral, and non-EA sovereign systems, respectively. Panel (d) presents the joint probability of default of the entire sovereign system. The sample period for all panels is from 1 January 2008 to 31 December 2013. 
(a) Core sovereigns

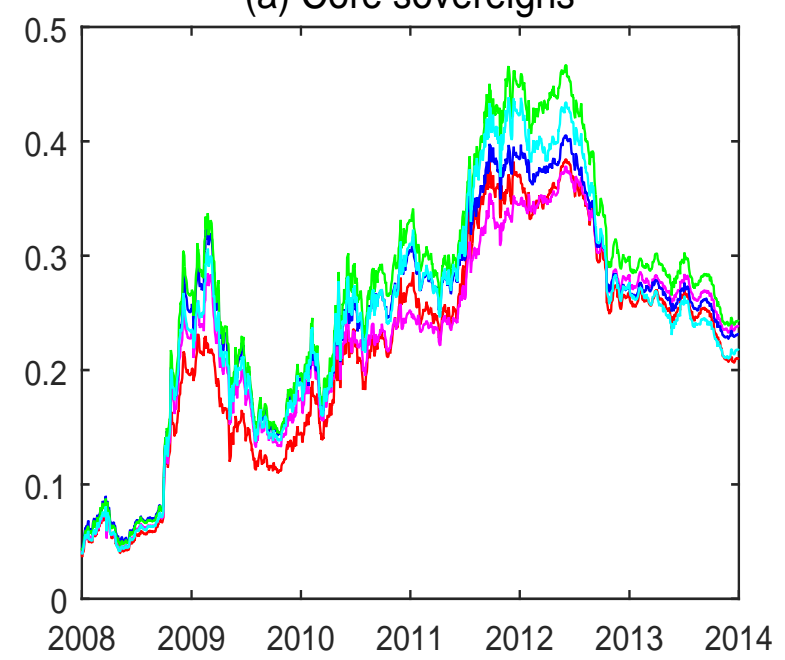

(b) Peripheral sovereigns

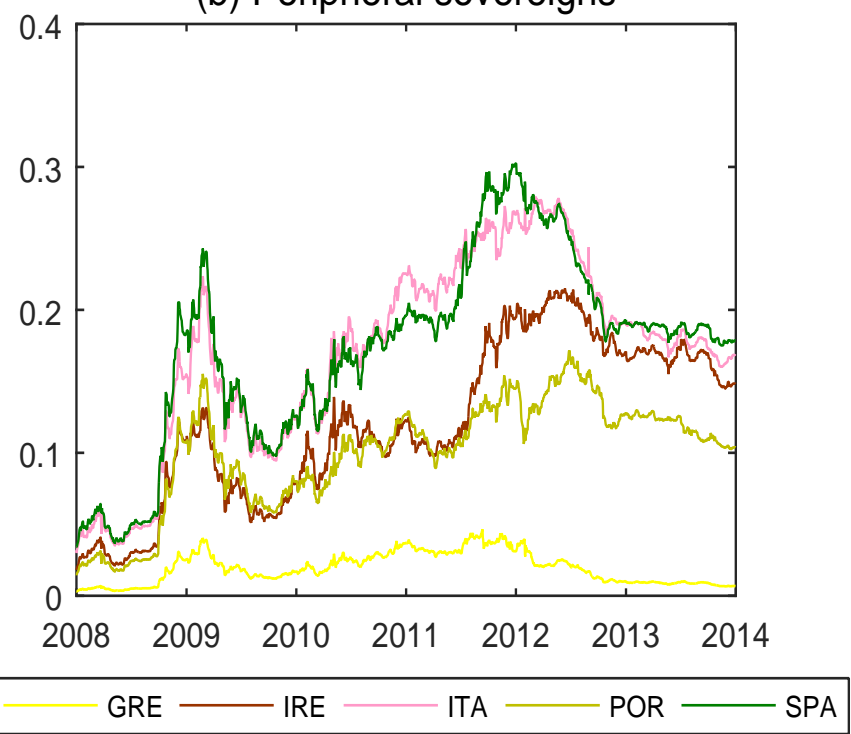

(c) Non-EA sovereigns

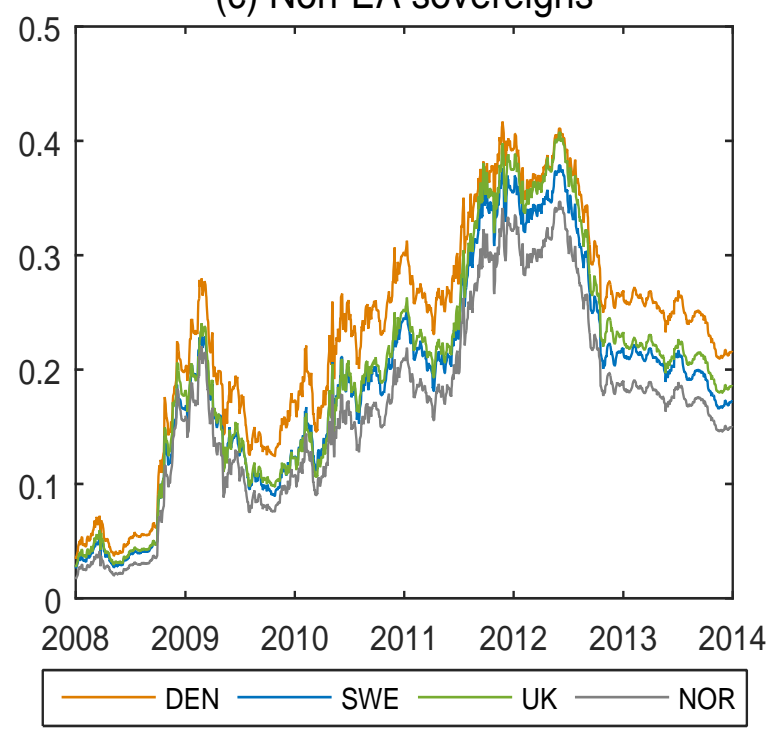

Figure 2. Conditional joint probability of default of the sovereign system, given the default of a particular sovereign. Note: Panels (a), (b), and (c) present the conditional joint probability of default of the sovereign system, given the default of each sovereign in the core, peripheral, and non-EA sovereign systems, respectively. The sovereign that defaults is indicated in the legend of each panel. The sample period for all panels is from 1 January 2008 to 31 December 2013. 
(a) Core sovereigns

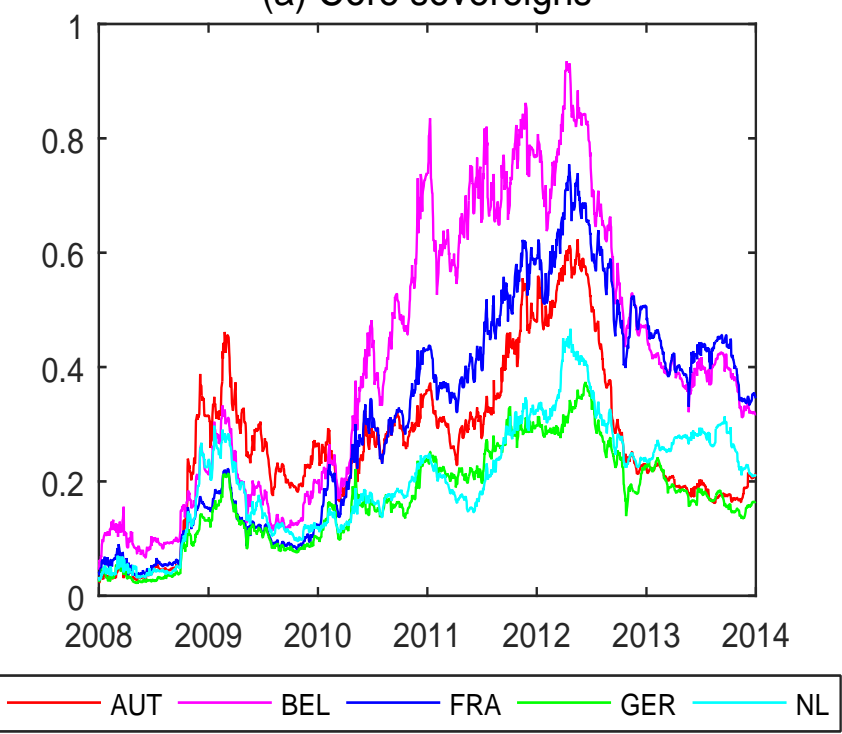

(b) Peripheral sovereigns

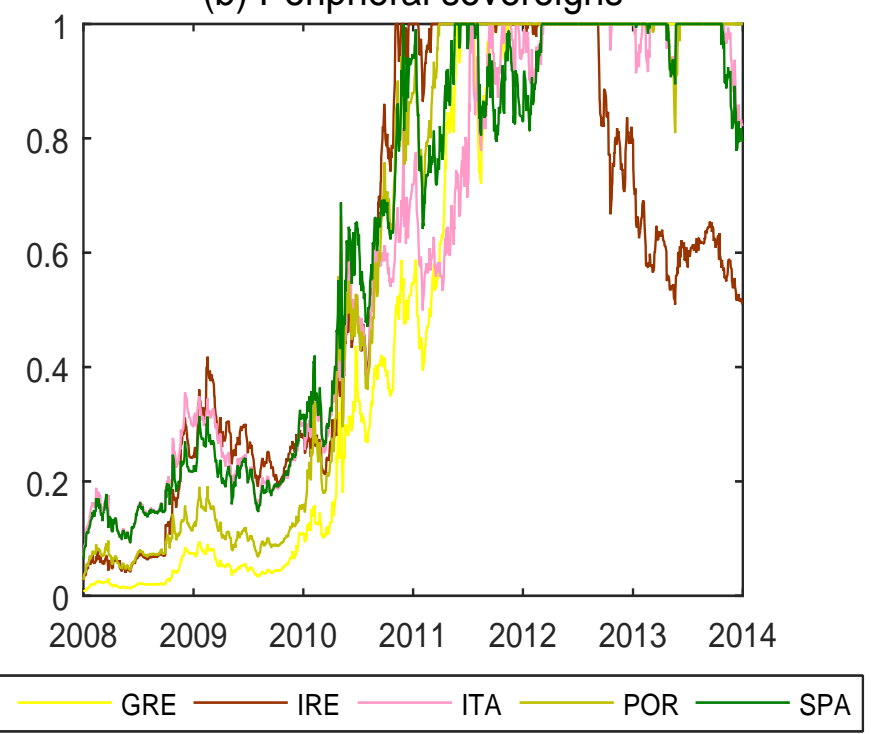

(c) Non-EA sovereigns

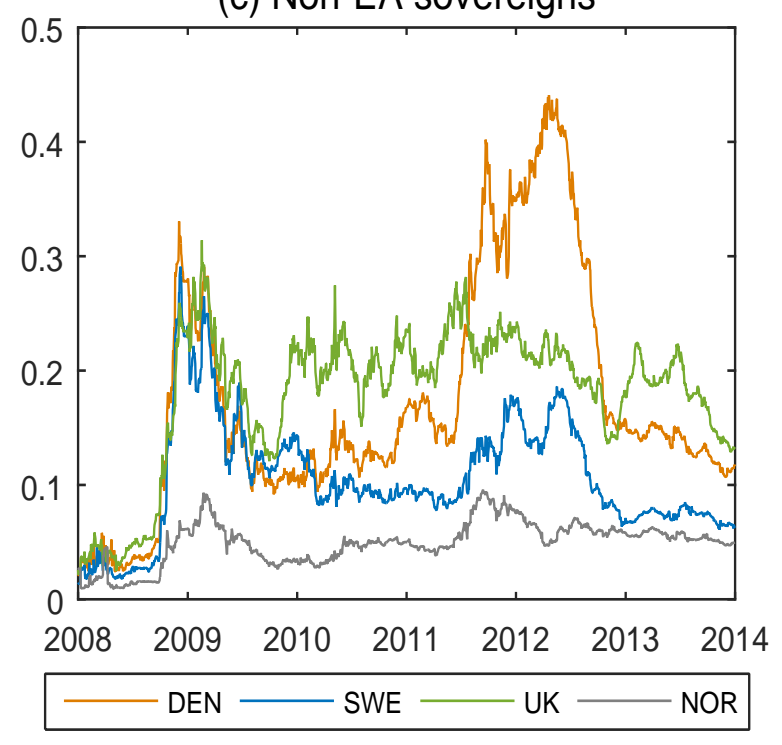

Figure 3. Conditional joint probability of default of a particular sovereign, given the default of the sovereign system excluding that sovereign. Note: Panels (a), (b), and (c) present the conditional joint probability of default of each sovereign in the core, peripheral, and non-EA sovereign systems, respectively, given the default of the sovereign system, excluding the sovereign in the legend of each panel. The sample period for all panels is from 1 January 2008 to 31 December 2013. 
(a) GRE

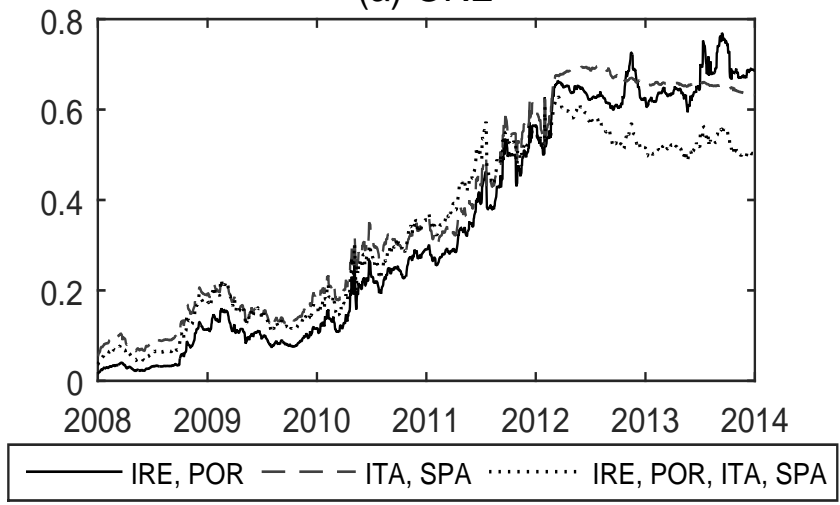

(c) ITA

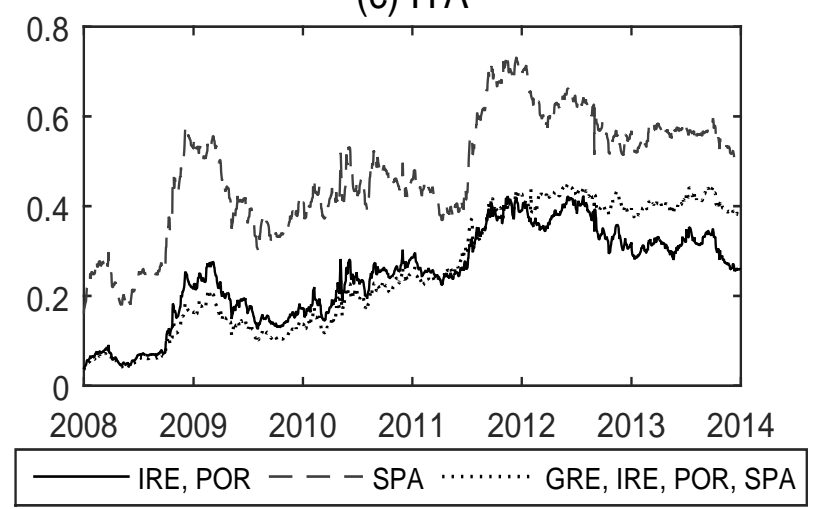

(b) IRE

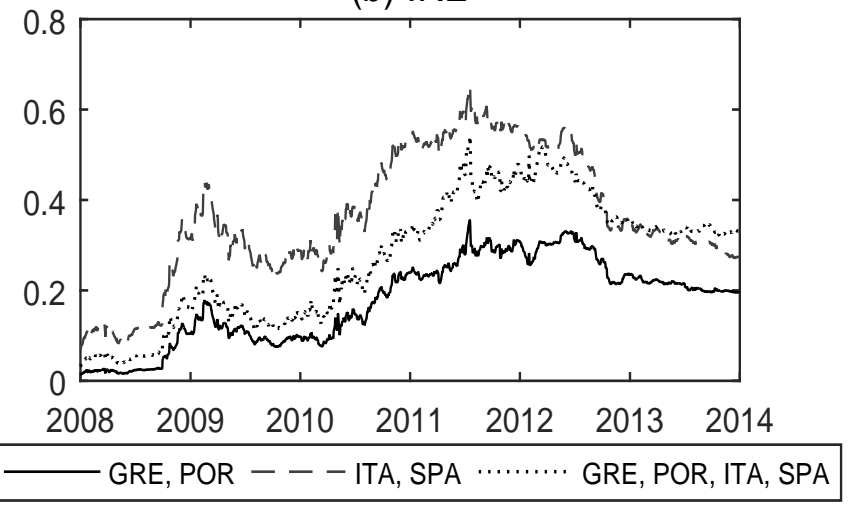

(d) POR

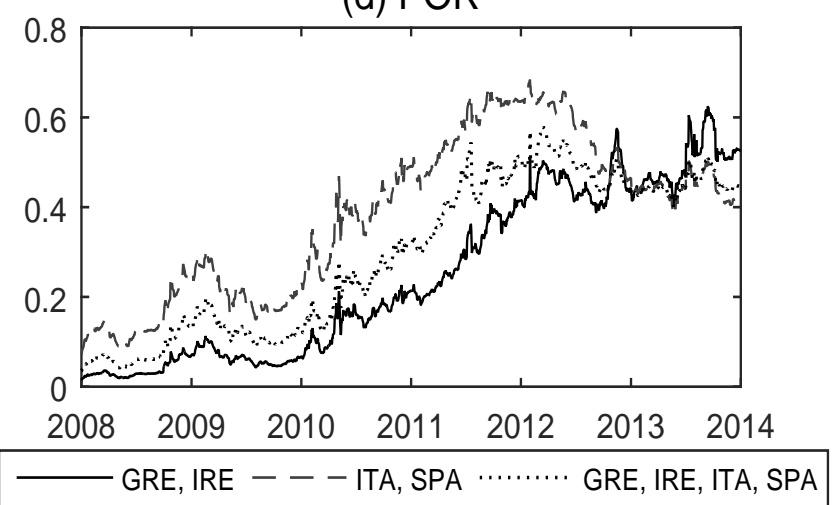

(e) SPA

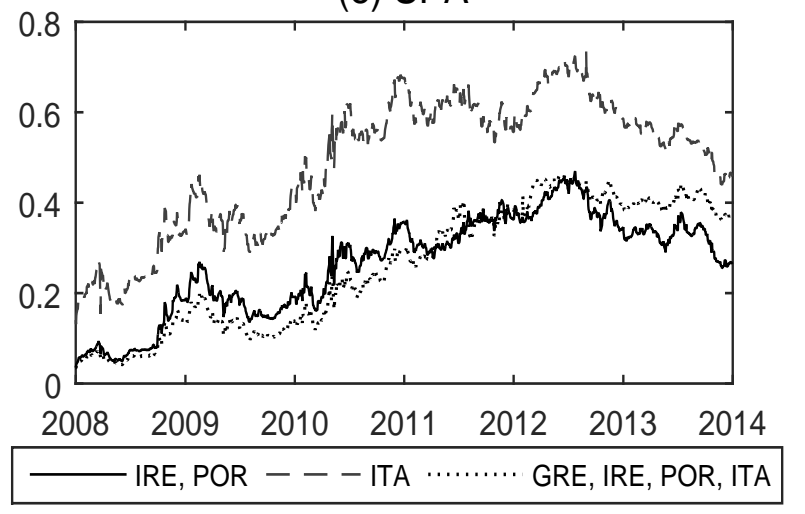

Figure 4. Conditional joint probability of default of a particular peripheral sovereign, given the default of other peripheral sovereigns. Note: Each panel presents the conditional joint probability of default of each of the five peripheral sovereigns (Greece, Ireland, Italy, Portugal, and Spain), given the default of the sovereigns listed in the legend. The sample period for all panels is from 1 January 2008 to 31 December 2013. 
(a) Two peripheral sovereigns

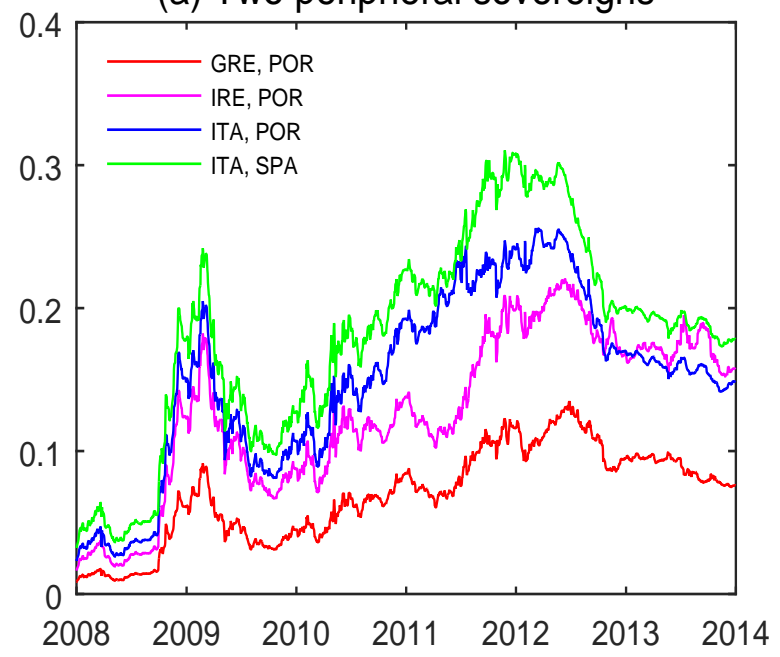

(c) Four peripheral sovereigns

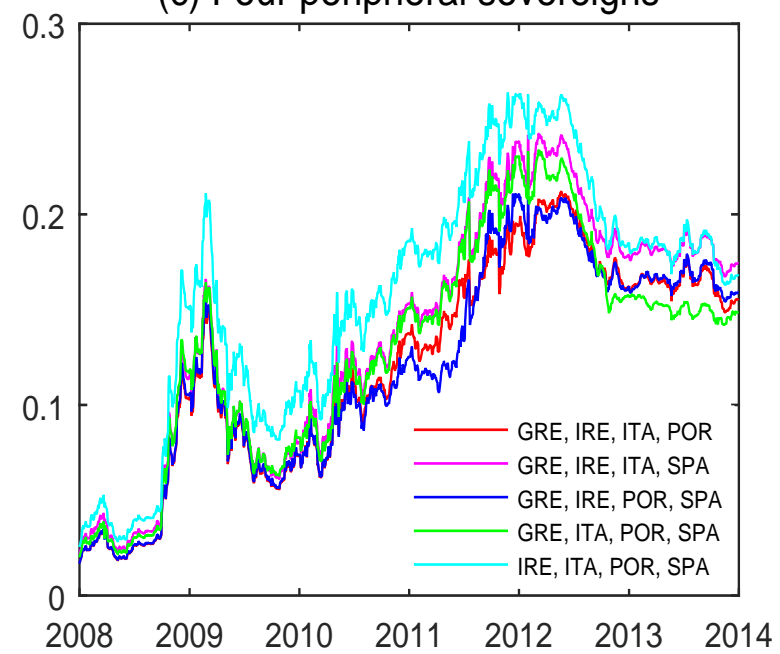

(b) Three peripheral sovereigns

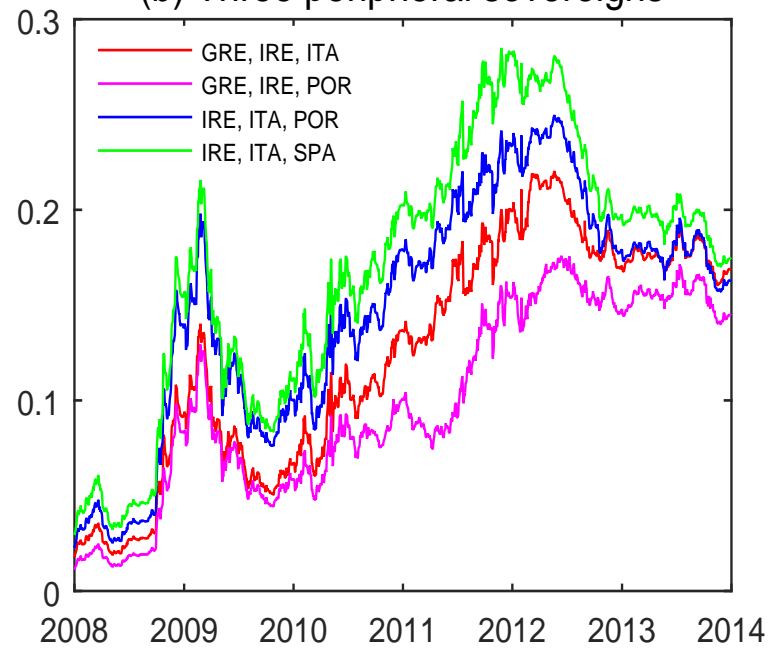

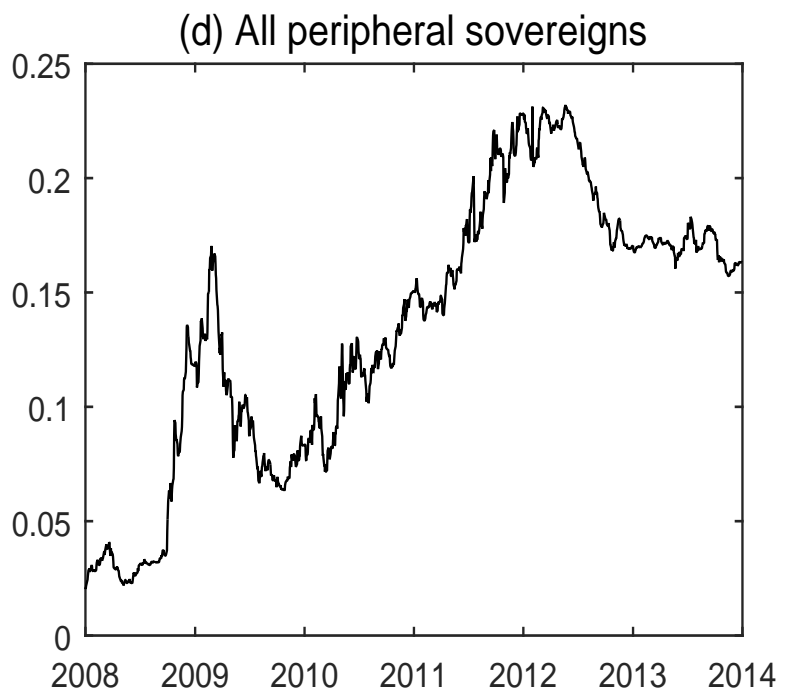

Figure 5. Conditional joint probability of default of the sovereign system, given the default of peripheral sovereigns. Note: Panels (a) to (c) present the conditional joint probability of default of the remaining sovereigns in the sovereign system, given the default of the peripheral sovereigns listed in the legend of each panel. Panel (d) presents the conditional joint probability of default of the remaining sovereigns in the sovereign system, given the default of all peripheral sovereigns. The sample period for all panels is from 1 January 2008 to 31 December 2013. 
(a) Core sovereigns

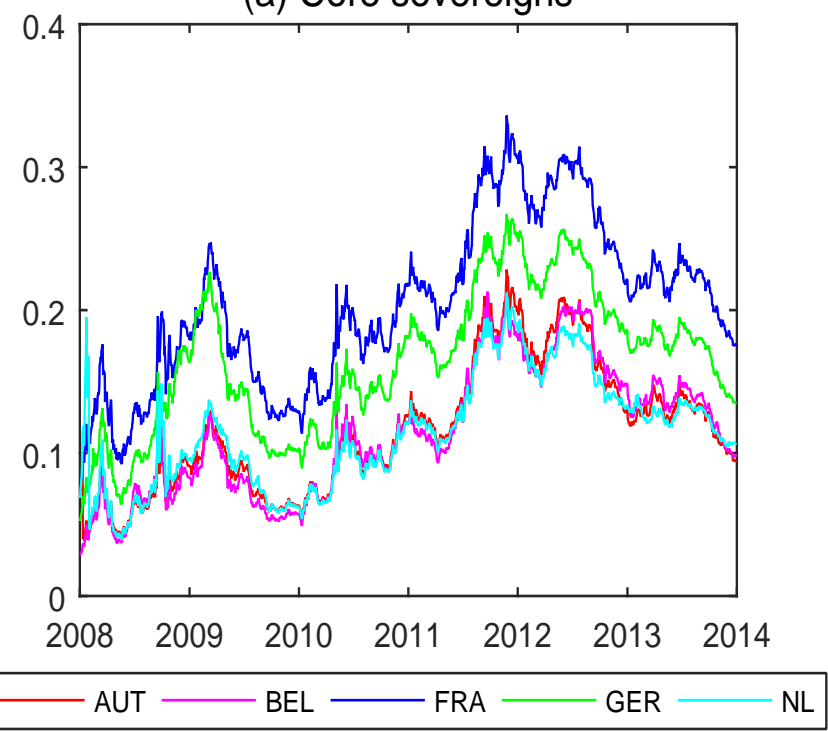

(b) Peripheral sovereigns

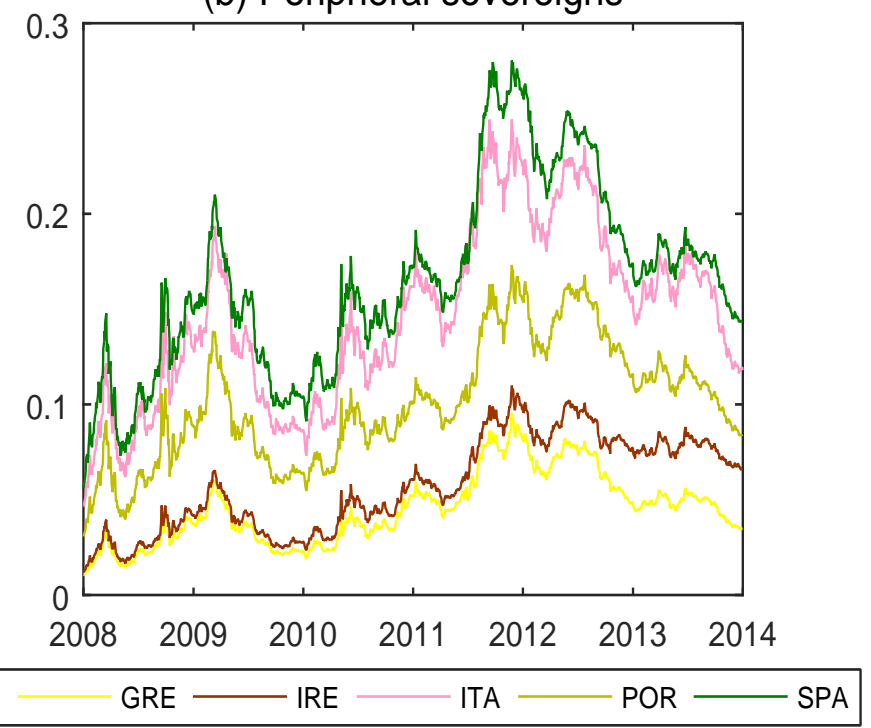

(c) Non-EA sovereigns

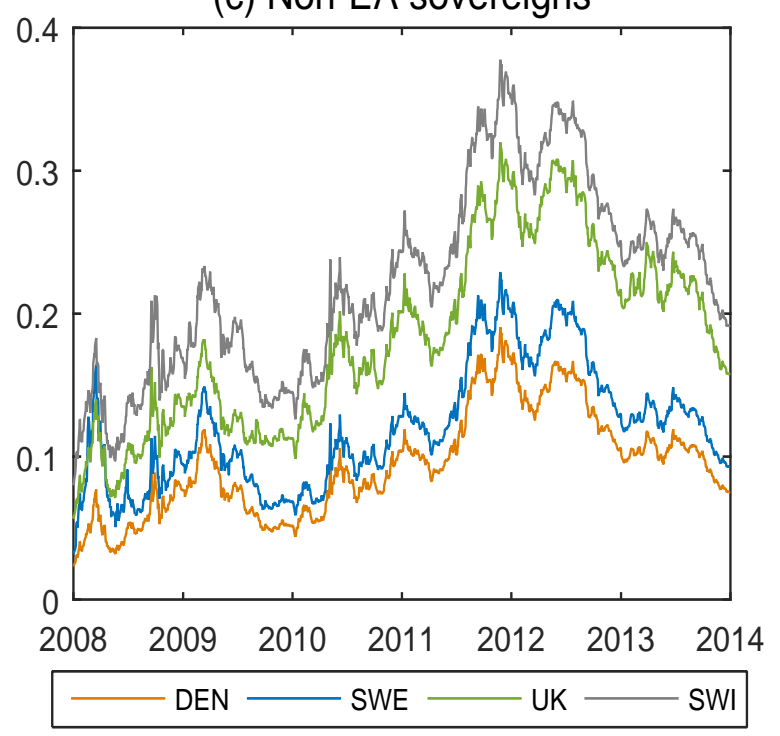

Figure 6. Conditional joint probability of default of the banking system, given the joint default of all banks in a particular sovereign. Note: Panels (a), (b), and (c) present the conditional joint probability of default of the banking system, given the joint default of all banks in each sovereign (listed in the legend of each panel) in the core, peripheral, and non-EA sovereign systems, respectively. The banks and their home country are listed in Table 1. The sample period for all panels is from 1 January 2008 to 31 December 2013. 
(a) Global Financial Crisis

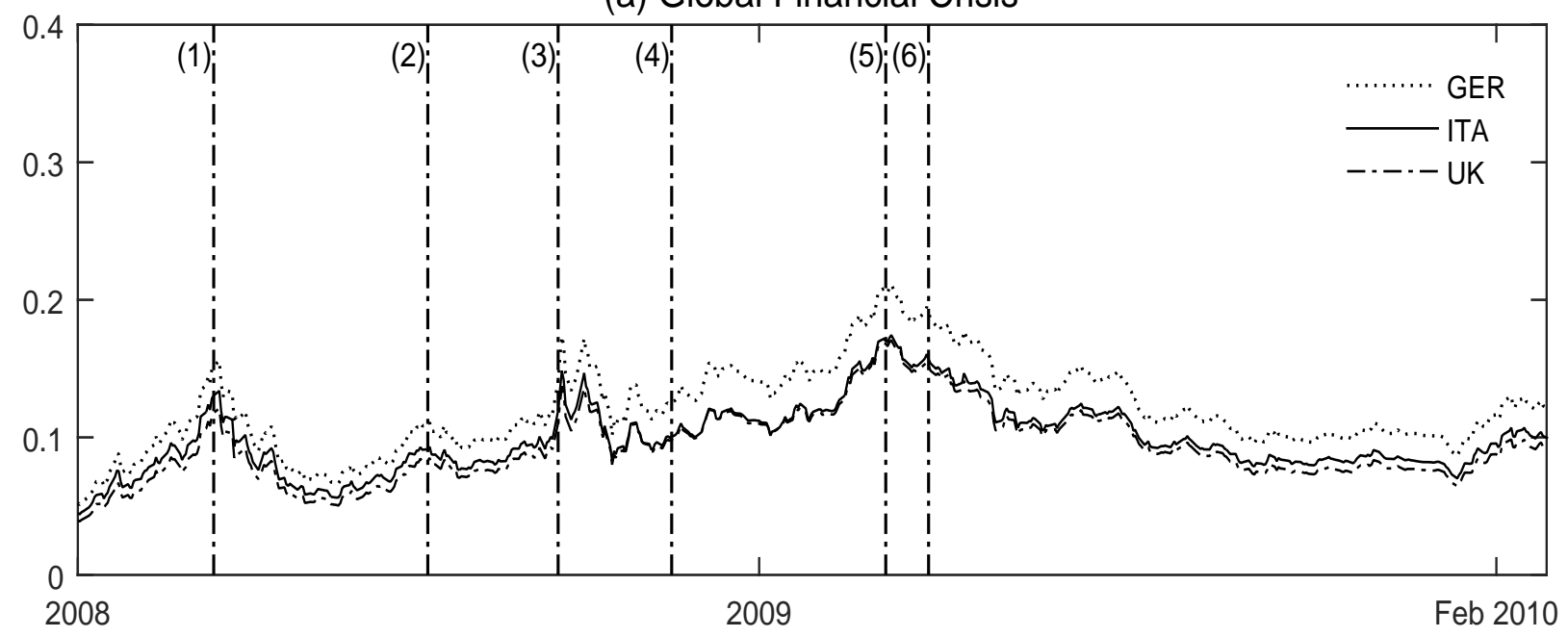

(b) Sovereign Debt Crisis

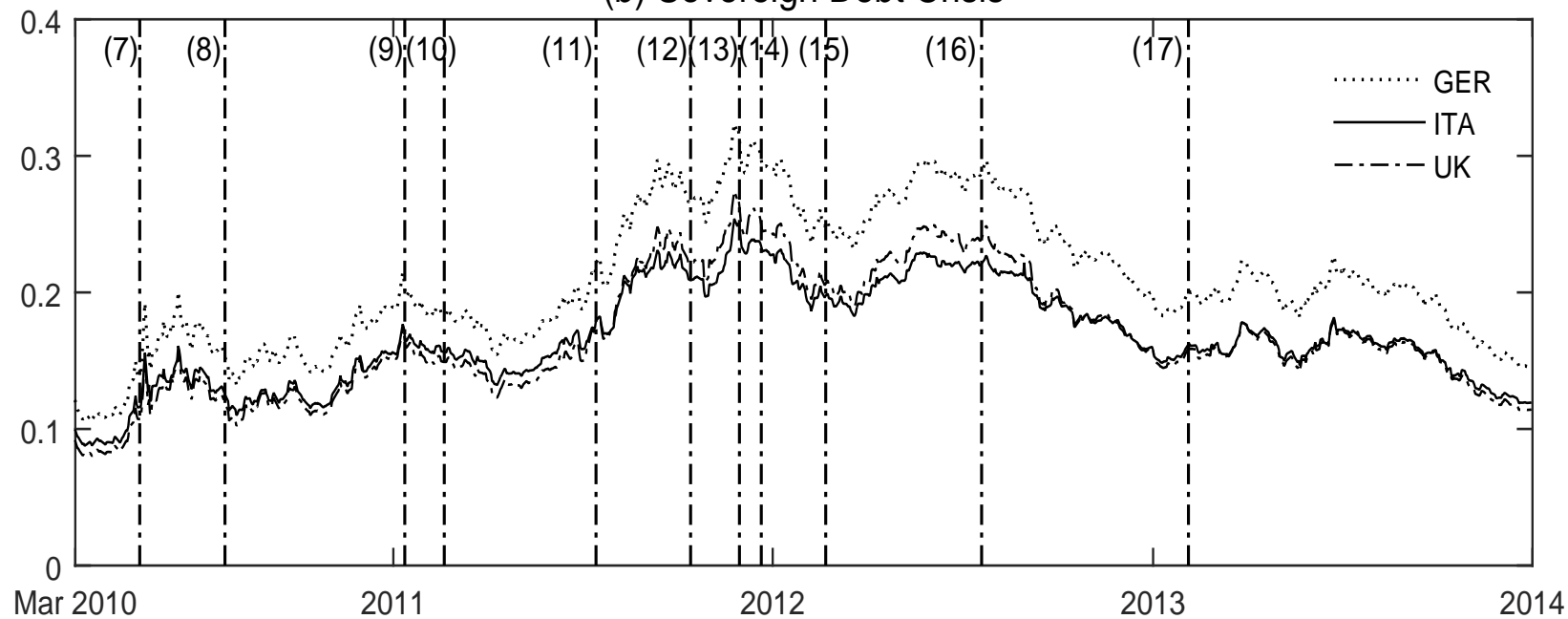

Figure 7. Conditional joint probability of default of the banking system, given the default of a particular sovereign during the global financial crisis and the sovereign debt crisis. Note: Panel (a) presents the conditional joint probability of default of the banking system, given the default of the sovereigns listed in the legend during the global financial crisis. Panel (b) presents the conditional joint probability of default of the banking system, given the default of the sovereigns listed in the legend during the sovereign debt crisis. The sample period for the first panel is from 1 January 2008 to 28 February 2010. The sample period for the second panel is from 1 March 2010 to 31 December 2013. Major events are denoted by dashed vertical lines and a brief description is provided in Appendix B. 
(a) Core sovereigns: CoJPoD

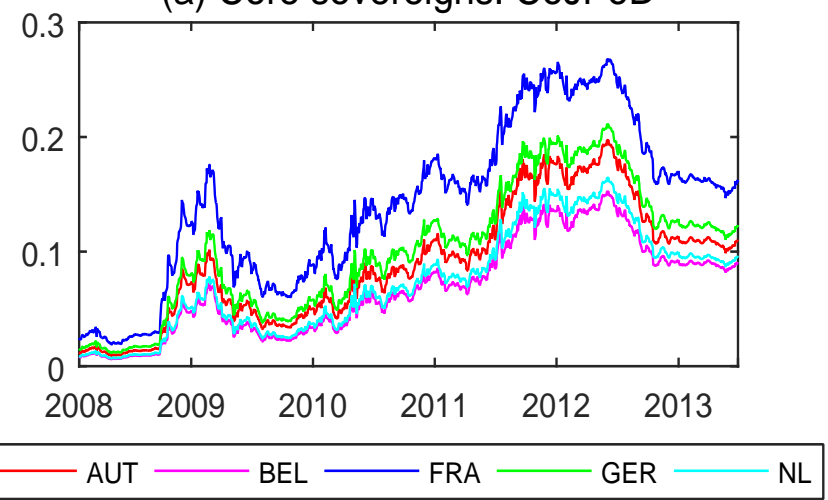

(c) Peripheral sovereigns: CoJPoD

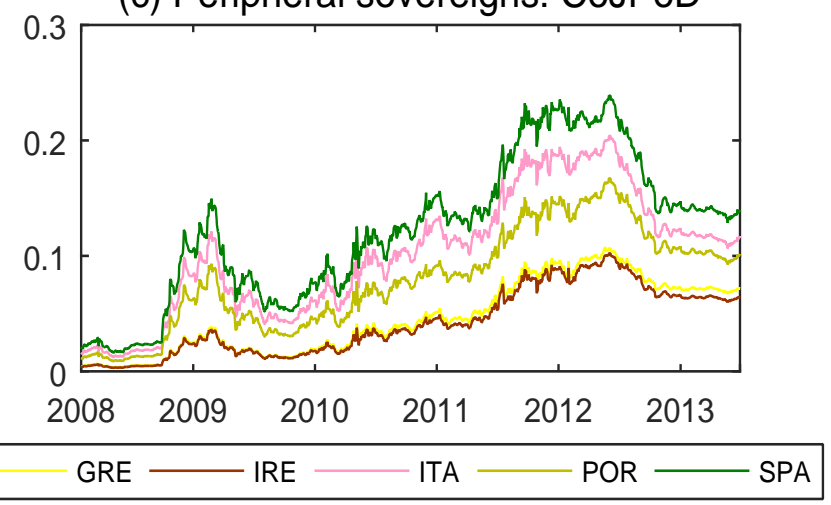

(e) Non-EA sovereigns: CoJPoD

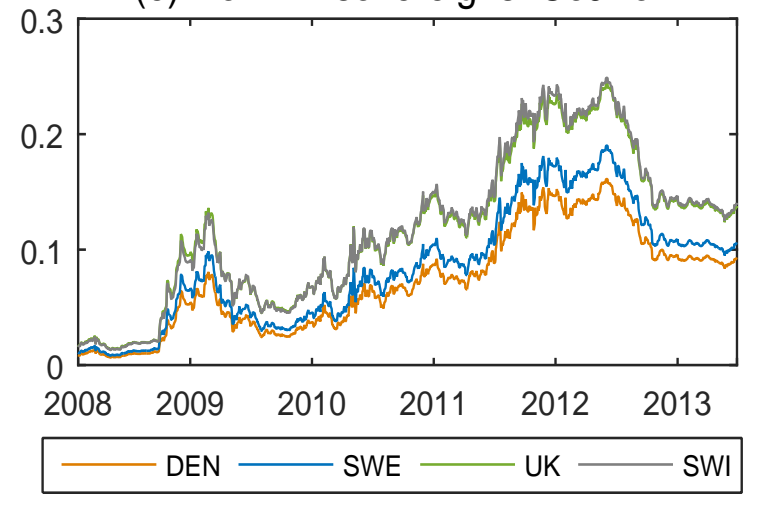

(b) Core sovereigns: DTD

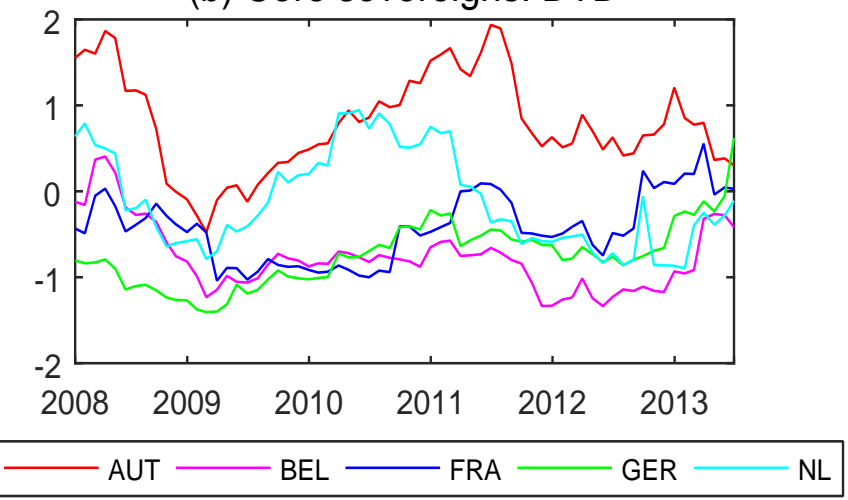

(d) Peripheral sovereigns: DTD

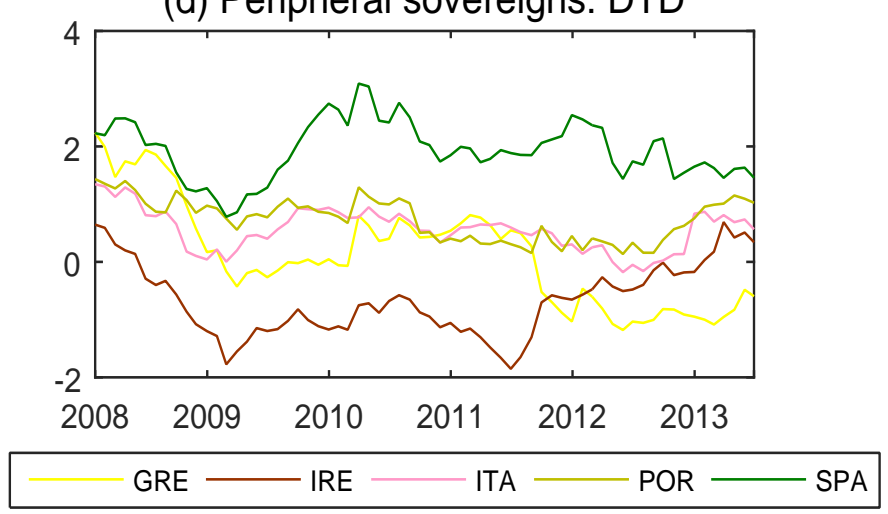

(f) Non-EA sovereigns: DTD

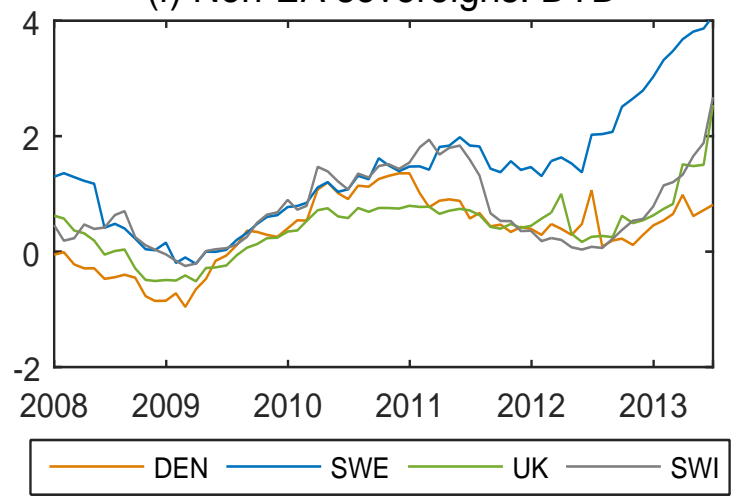

Figure 8. Conditional joint probability of default of the sovereign system, given the joint default of all banks in a particular sovereign and the average DTD. Note: Panels (a), (c), and (e) present the conditional joint probability of default of the sovereign system, given the joint default of all banks in each sovereign (listed in the legend of each panel) in the core, peripheral, and non-EA sovereign systems, respectively. Panels (b), (d), and (f) present the average DTD of all banks in each sovereign (listed in the legend of each panel) in the core, peripheral, and non-EA sovereign systems, respectively. The sample period is from 1 January 2008 to 1 July 2013. 
(a) Core sovereigns

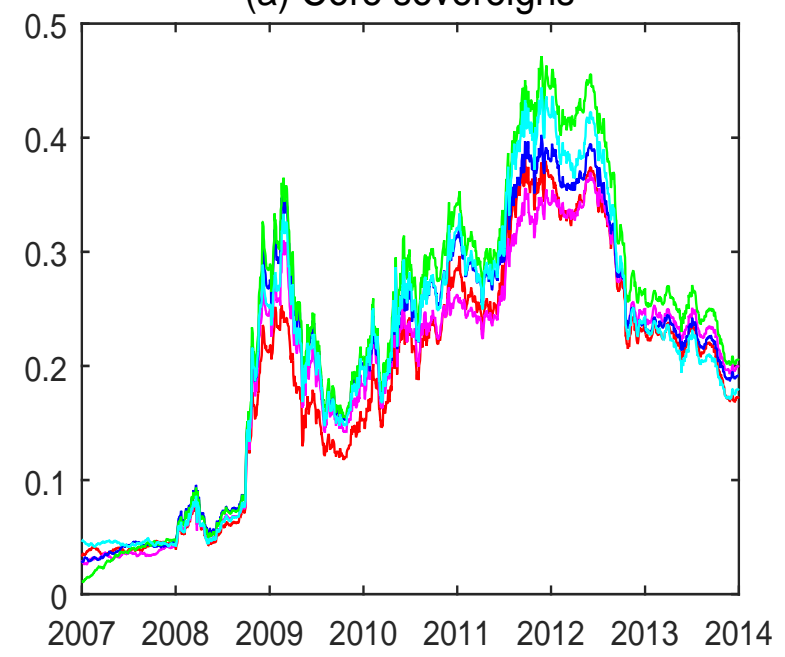

(b) Peripheral sovereigns

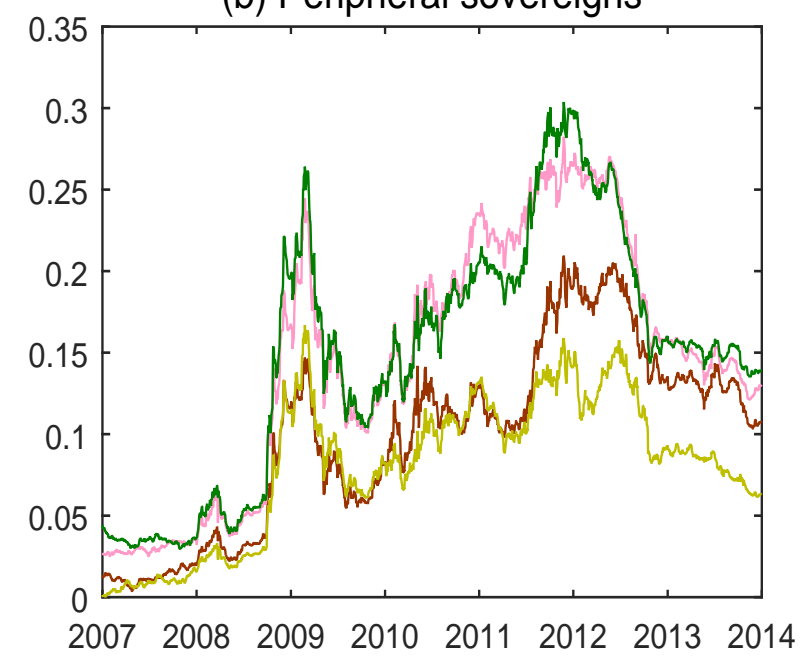

$\mathrm{NL}$

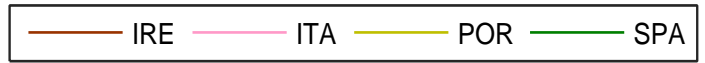

(c) Non-EA sovereigns

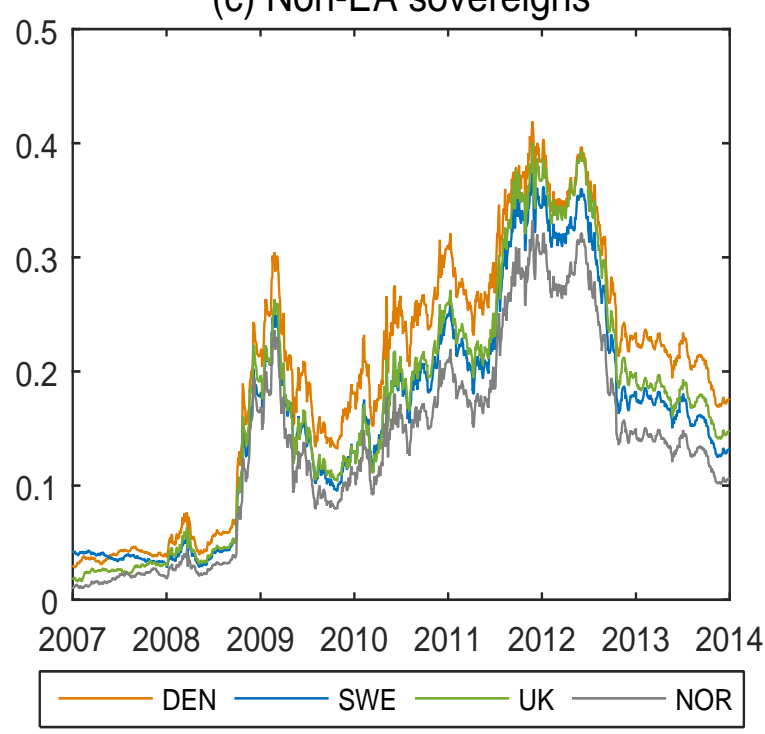

Figure 9. Conditional joint probability of default of the sovereign system excluding Greece, given the default of a particular sovereign. Note: Panels (a), (b), and (c) present the conditional joint probability of default of the sovereign system excluding Greece, given the default of each sovereign in the core, peripheral, and non-EA sovereign systems, respectively. The sovereign that defaults is indicated in the legend of each panel. The sample period for all panels is from 1 January 2007 to 31 December 2013. 
(a) IRE

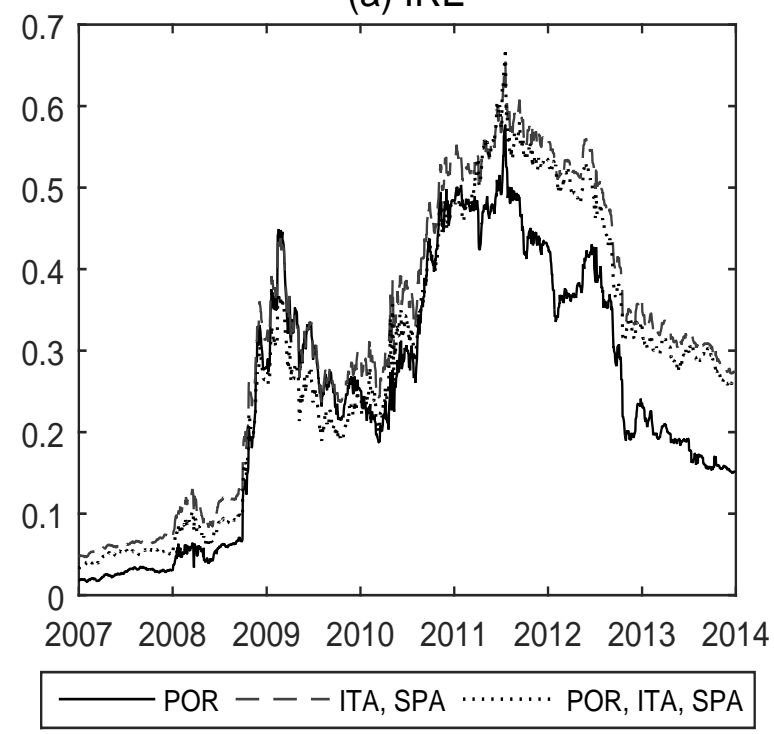

(c) POR

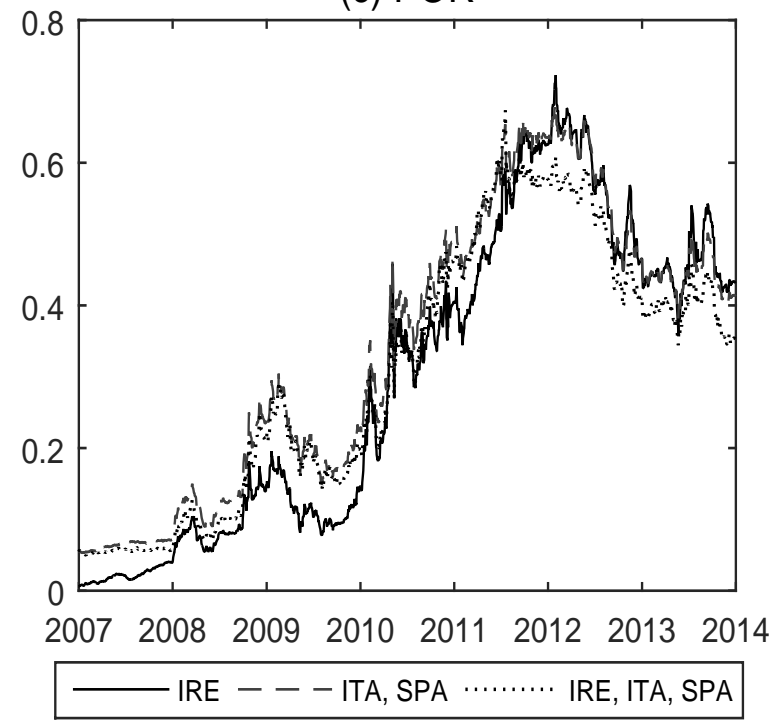

(b) ITA

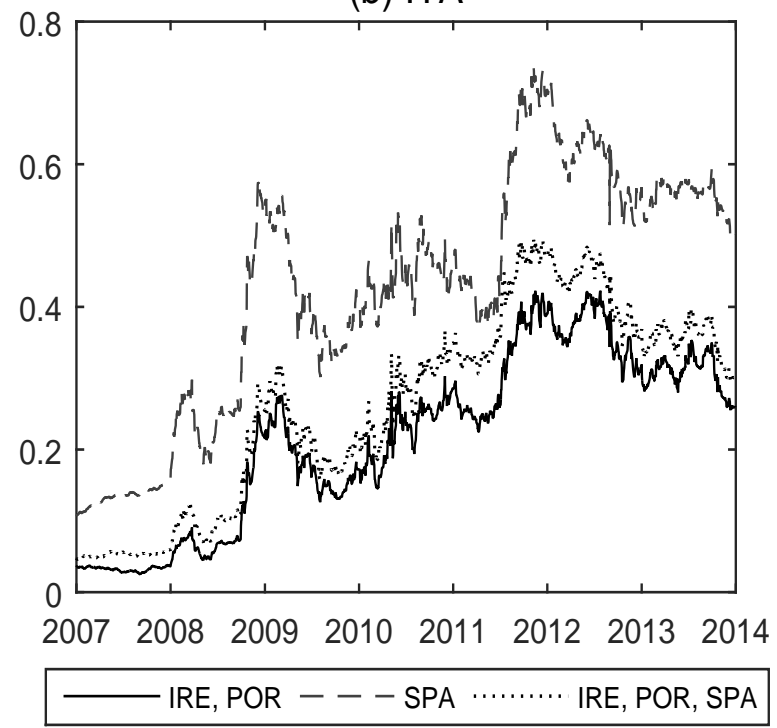

(d) SPA

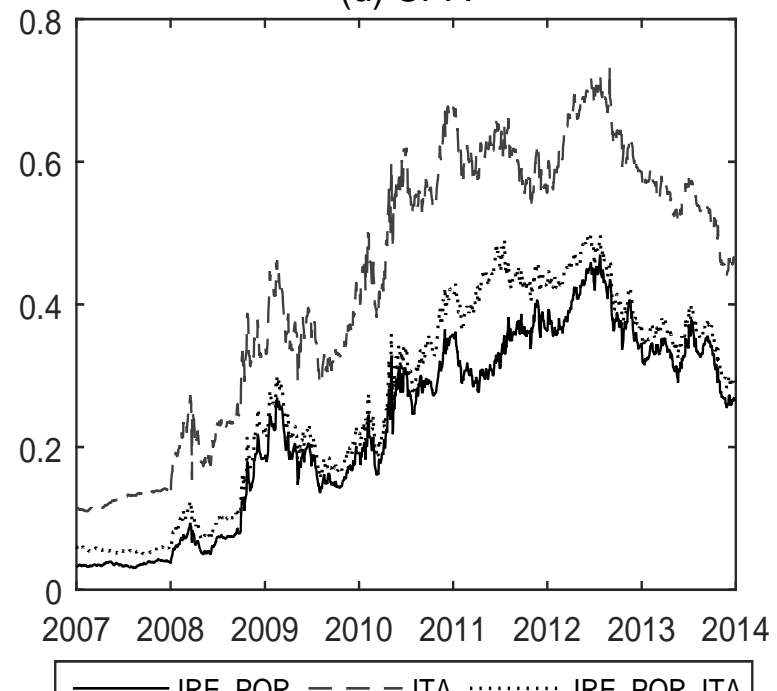

Figure 10. Conditional joint probability of default of a particular peripheral sovereign, given the default of other peripheral sovereigns, excluding Greece. Note: Each panel presents the conditional joint probability of default of each of the four peripheral sovereigns (Ireland, Italy, Portugal, and Spain), given the default of the sovereigns listed in the legend. Greece is excluded from the peripheral sovereign system. The sample period for all panels is from 1 January 2007 to 31 December 2013. 
(a) Three peripheral sovereigns

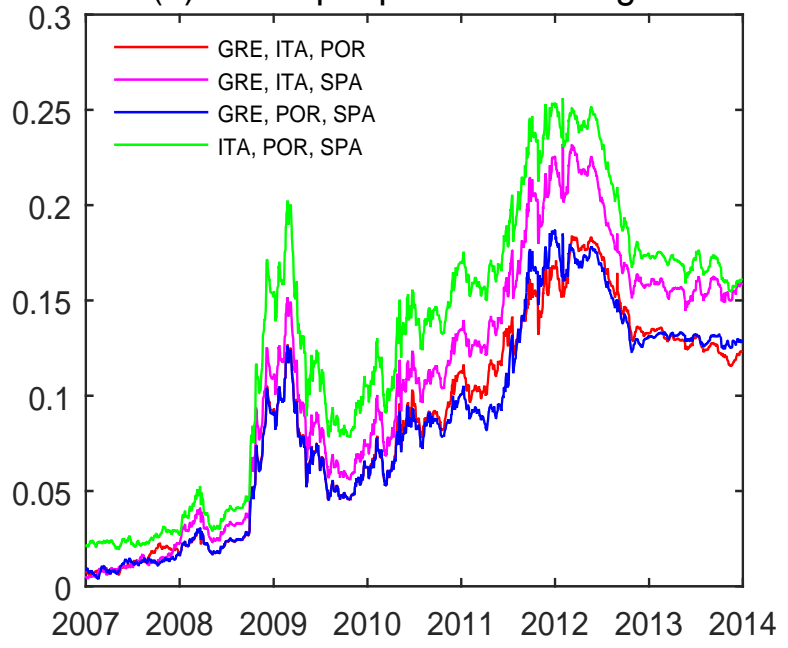

(b) Four peripheral sovereigns

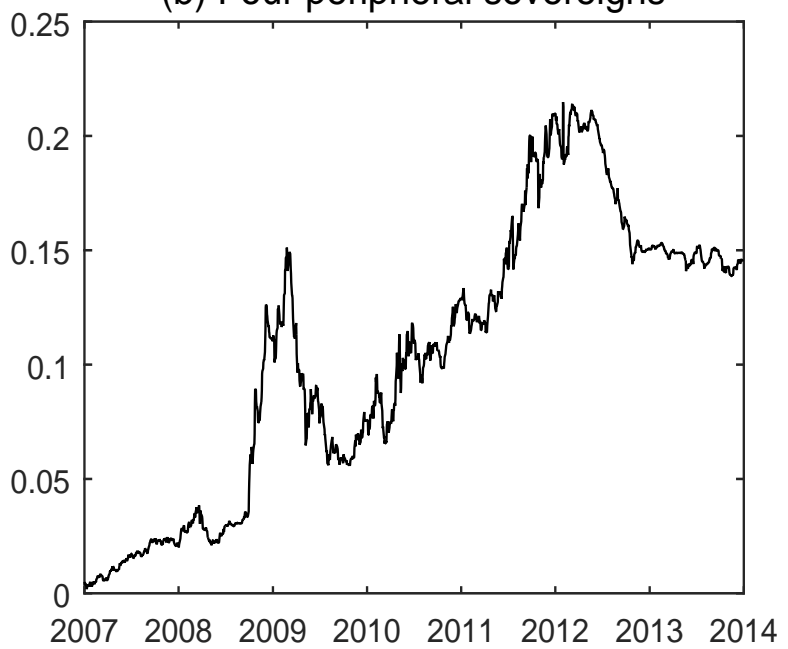

Figure 11. Conditional joint probability of default of the sovereign system, given the default of peripheral sovereigns, excluding Ireland. Note: Panel (a) presents the conditional joint probability of default of the remaining sovereigns in the sovereign system excluding Ireland, given the default of the peripheral sovereigns listed in the legend. Panel (b) presents the conditional joint probability of default of the remaining sovereigns in the sovereign system, given the default of all four peripheral sovereigns, excluding Ireland. The sample period for all panels is from 1 January 2007 to 31 December 2013. 
(a) Core sovereigns

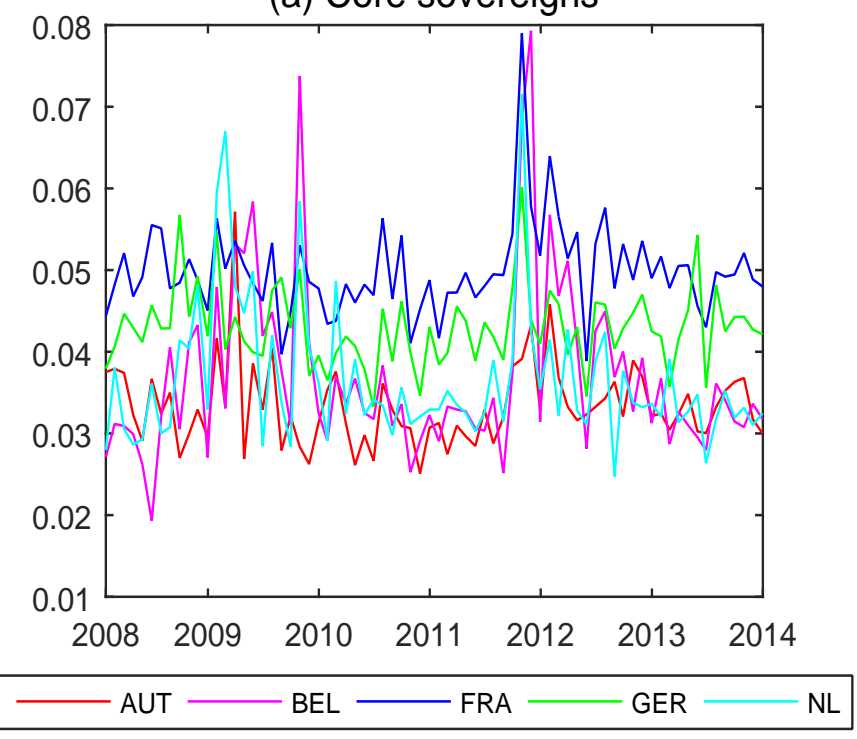

(b) Peripheral sovereigns

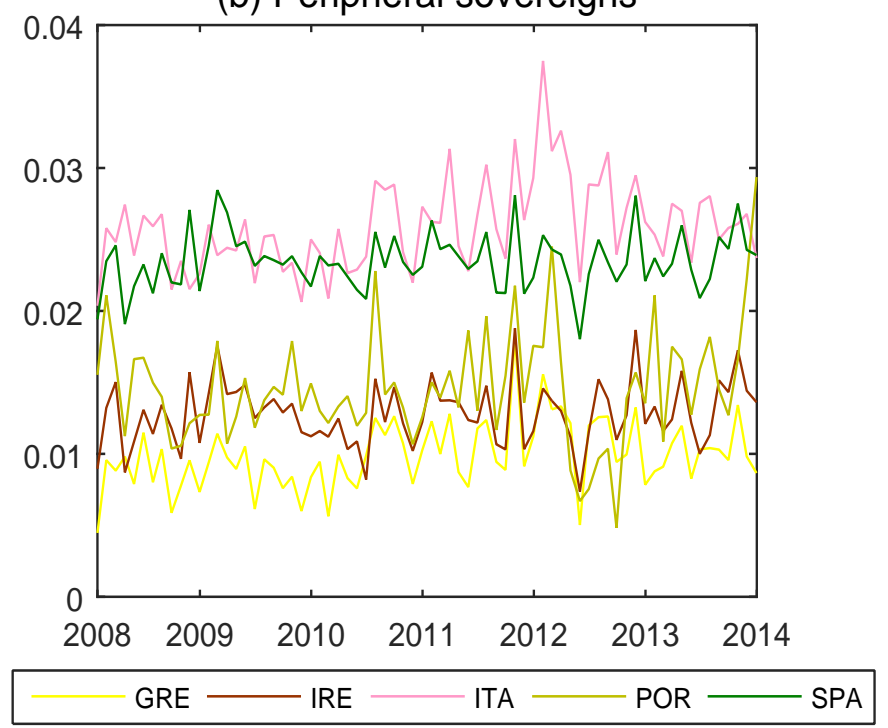

(c) Non-EA sovereigns

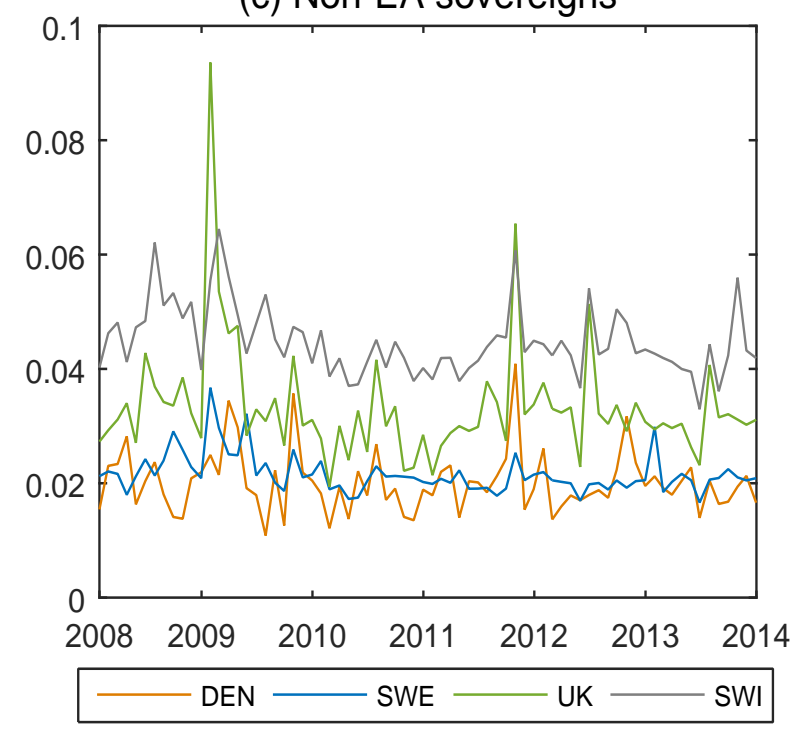

Figure 12. Average MES of all banks in a particular sovereign. Note: Panels (a), (b), and (c) present the average MES of all banks in each sovereign (listed in the legend of each panel) in the core, peripheral, and non-EA sovereign systems, respectively. The banks and their home country are listed in Table 1. The sample period for all panels is from 1 January 2008 to 31 December 2013. 